\title{
Impact of climate change on flood characteristics in Brahmaputra basin using a macro-scale distributed hydrological model
}

\author{
Shyamal Ghosh and Subashisa Dutta* \\ Department of Civil Engineering, Indian Institute of Technology Guwahati, Guwahati 781 039, India. \\ ${ }^{*}$ Corresponding author. e-mail: subashisa@iitg.ac.in
}

Being the highest specific discharge river system in the world, the Brahmaputra river experiences a number of long-duration flood waves during the monsoon season annually. In order to assess the flood characteristics at the basin and tributary scales, a physically based macro-scale distributed hydrological model (DHM) has been calibrated and validated for 9 wet years. The model performance has been evaluated in terms of prediction of the flood characteristics such as peak discharge, flood duration, arrival time of flood wave, timing of the peak flow and number of flood waves per season. Future changes in the flood wave characteristics of the basin have been evaluated using the validated model with bias-corrected future-projected meteorological scenario from a regional climate model (RCM). Likelihood analysis of the simulated flow time series reveals that significant increase in both peak discharge and flood duration is expected for both the pre-monsoonal and monsoonal seasons in the basin, but the number of flood waves per season would be reduced. Under the projected climate change scenario, it is expected that there will be more catastrophic floods in the basin.

\section{Introduction}

The temperature of planet Earth has shown an increasing trend, particularly since the 1920s. Number of warm years in the recent period have exceeded the expected range of natural variability (Hadley Centre 1997). The mean surface temperature of planet Earth is expected to rise at a rate of $0.3-0.6^{\circ} \mathrm{C}$ per decade in the present century (IPCC 2001). Change in temperature alters major hydrological processes in the water cycle. As a result, the spatio-temporal variation of water resources in a river basin is likely to be changed (Kundzewicz et al 2007). Not only that, flood vulnerability in a river basin would be altered.
One of the large river basins, the Brahmaputra river, also ranked as the highest specific discharge system in the world (Datta and Singh 2004), has large flood-prone areas. During flood season, there are a number of long-duration flood waves that pass through the main river (Karmaker and Dutta 2010) and some of its tributaries are flashy in nature. Generally, flood vulnerability of a river reach is quantified with respect to the occurrence and increase in peak flows. In this river, the characteristics of flood waves such as flood duration, peak discharge, timing of peak and number of flood waves per season mainly define the flood vulnerability. Not only that, the availability of long-term measured hydrological time series data is another

Keywords. Climate change; PRECIS; natural hazards; flood characteristics; hydrology; Brahmaputra basin. 
issue with regard to this river basin. An appropriate hydrological model is thus required to estimate the spatio-temporal variation of floods.

Use of hydrological models for estimating peak flows and annual water yield has been attempted in many river basins. As spatial input data such as land use/land cover, digital elevation model and distribution of soil properties are the most critical input for a hydrological model and a number of distributed hydrological models like r. water. fea (Vieux and Gauer 1994; Vieux 2001), CASC2D (Julien and Saghafian 1991; Ogden and Julien 1994; Julien et al 1995), Systeme Hydrologique European (SHE) (Abbott et al 1986) and the Distributed Hydrology Soil Vegetation Model (Wigmosta et al 1994), and many other models (Rogers et al 1985; Bathurst 1986; Vieux et al 2004), have been developed to consider these critical inputs for obtaining the spatio-temporal variation of flood generation and propagation in the river basins. However, application of these models is limited to the river basins with precise hydrological database. In the Brahmaputra basin, vegetated hillslopes, waterlogged paddy agricultural fields and wetlands are major land use/land cover classes. Most of these models have not considered the hydrological processes in these classes explicitly. Considering these facts, a distributed hydrological model, focusing on surface and subsurface hydrological processes in these classes was conceptualized, developed and validated for estimating the hydrological response of a river catchment (Dutta and Zade 2003; Mishra et al 2008). This model has two more advantages: the required spatial input data for a river basin are mostly available and fewer calibration parameters. In this study, this model is used to obtain the flood characteristics of the Brahmaputra with limited spatial and aspatial input dataset.

Possible future changes in the flood wave characteristics can be obtained by carrying out hydrological modelling using future projected meteorological datasets. General circulation models (GCM) are frequently used for predicting the future meteorological variation. Similar studies on the effect of climate change on floods has been carried out in different countries and regions (Cameron et al 2000; Reynard et al 2001; Arora and Boer 2001; Kay et al 2006; Wang et al 2006; Chang and Jung 2010; Vastila et al 2010). Future flood scenarios in Bangladesh have been assessed considering the change in flood regime in GangaBrahmaputra-Meghna basin due to climate change (Mirza 2002; Mirza et al 2003; Gain et al 2011) using an empirical rainfall-runoff relationship. However, the coarse spatial resolution of the GCM output is not appropriate for use in a hydrological model for predicting the flood wave characteristics.
Regional climate models (RCM) have been recently used to obtain the required resolution (Kay et al 2006; Wang et al 2006; Akhtar et al 2009), even though sometimes the resolution of an RCM is not fine enough and creates some bias in the spatial distribution of climate variables. In the present study, projected meteorological (rainfall and temperature) variables from a regional climate model (PRECIS) simulation have been used to simulate the hydrological model to predict the changes in the characteristics of flood waves in the basin.

In all these previous studies, different meteorological and hydrological models were used with different spatial and temporal scales. But in almost all the cases the emphasis was on the changes of peak discharge, flood volume and annual water yield. The future changes of characteristics of the flood waves have not yet been addressed with its due importance in a large river basin. In the present study, the spatio-temporal variability of the floods in the Brahmaputra basin has been addressed with its due importance in a large river basin. A likelihood analysis on the model simulated time series was carried out to obtain the general trend and extent of changes in the flood characteristics.

A brief description of the characteristics of the study area follows. The methodology section includes a brief description of the hydrological model used, the input data and model parameters and the depiction of the projected climate change scenario. The results and discussion section consists of calibration, validation and performance analysis of the hydrological model followed by the analysis of the results related to the effect of projected climate change on the flood characteristics. Finally, the likelihood analysis of the results is followed by our conclusions.

\section{Study area}

\subsection{Basin characteristics}

The Brahmaputra, being one of the largest rivers in the world, with drainage area of $580,000 \mathrm{~km}^{2}$, of which $194,000 \mathrm{~km}^{2}$ is in India, has a huge impact on the socio-economic status as well as the hydrology of the region. The average annual runoff in the Brahmaputra is $537.2 \mathrm{~km}^{3}$ (Sarma 2004). In its course of about $2900 \mathrm{~km}$, it drains through a number of different and diverse environments. Originating from the cold dry plateau of Tibet, where it is known as Tsangpo, it flows through the Himalayan slopes to enter India at an elevation of $660 \mathrm{~m}$ and flows in a southern course for about $220 \mathrm{~km}$ to reach Pasighat. After confluencing with two major tributaries, Dibang and Lohit, at Pasighat, the river is now called Brahmaputra 
and flows through the alluvial plains of Assam valley for about $710 \mathrm{~km}$, and enters the deltaic plains of Bangladesh to deplete into the Bay of Bengal. The river gets runoff contribution from more than 100 tributaries of which 15 in the north-bank and 10 in the south-bank are fairly large (Sarma 2004). Among all these tributaries, three trans-Himalayan tributaries in the north, viz., Subansiri, Jia Bhoroli and Manas rivers, have drainage areas more than $10,000 \mathrm{~km}^{2}$, whereas Dhansiri (S) and Kopili rivers on the south bank also have drainage areas more than $10,000 \mathrm{~km}^{2}$. The basin map along with its drainage network is shown in figure 1.

The river has very gentle bed gradient in its lower reaches, falling at the rate of $0.079 \mathrm{~m}$ per $\mathrm{km}$, while in the Himalayan region the channel is narrow and has a gradient as high as $16.8 \mathrm{~m}$ per $\mathrm{km}$ (Sarma 2005). The average annual discharge of the river is reported to be $19,820 \mathrm{~m}^{3} / \mathrm{s}$ at Goalundo in Bangladesh (Datta and Singh 2004). In the alluvial plains of north-eastern India, the Brahmaputra flows in a highly braided channel along with a large number of mid-channel and lateral bars. The average width of the Brahmaputra varies from 6 to $18 \mathrm{~km}$ with a few nodal (constraint) reaches such as Tezpur of width $3.6 \mathrm{~km}$ and Guwahati of width $1.2 \mathrm{~km}$. Since it is a large braided river, daily water levels (gauge) are being measured at these nodal reaches. Bed level aggradation/degradation commonly occurs at the nodal reaches throughout a year.
For the present study, three river gauging stations have been considered for the analysis of simulation data. These three river gauging stations are located at Tezpur, Guwahati and Dhubri. The gauging station of Tezpur is located in the upper part of the middle reach of the Brahmaputra. Chainage distance of Tezpur from the confluence of the river to the Bay of Bengal is $672 \mathrm{~km}$. Guwahati (chainage $542 \mathrm{~km}$ ) and Dhubri (chainage $357 \mathrm{~km}$ ) near the Indo-Bangladesh border are the other two river gauging stations considered.

\subsection{Meteorological characteristics}

The general circulation over the basin area undergoes abrupt seasonal changes during late spring and early summer due to tropospheric warming over the Asian landmass, and causes early summer rains over the basin (He et al 1987). The mean annual value of such pre-monsoonal heavy rains shows a rainfall above $100 \mathrm{~mm} /$ day for 7.7 days and above $300 \mathrm{~mm}$ /day for 1.6 days for the observation period of 1993-2001 (Soja and Starkel 2007).

The river basin receives high-intensity storm events frequently during the four monsoon months from June to September. Clusters of successive several rainy days are very frequent during the monsoon season. In the Cherapunji region in the basin, on an average 28.3 days with rainfall above $100 \mathrm{~mm} /$ day and 5 days with rainfall above

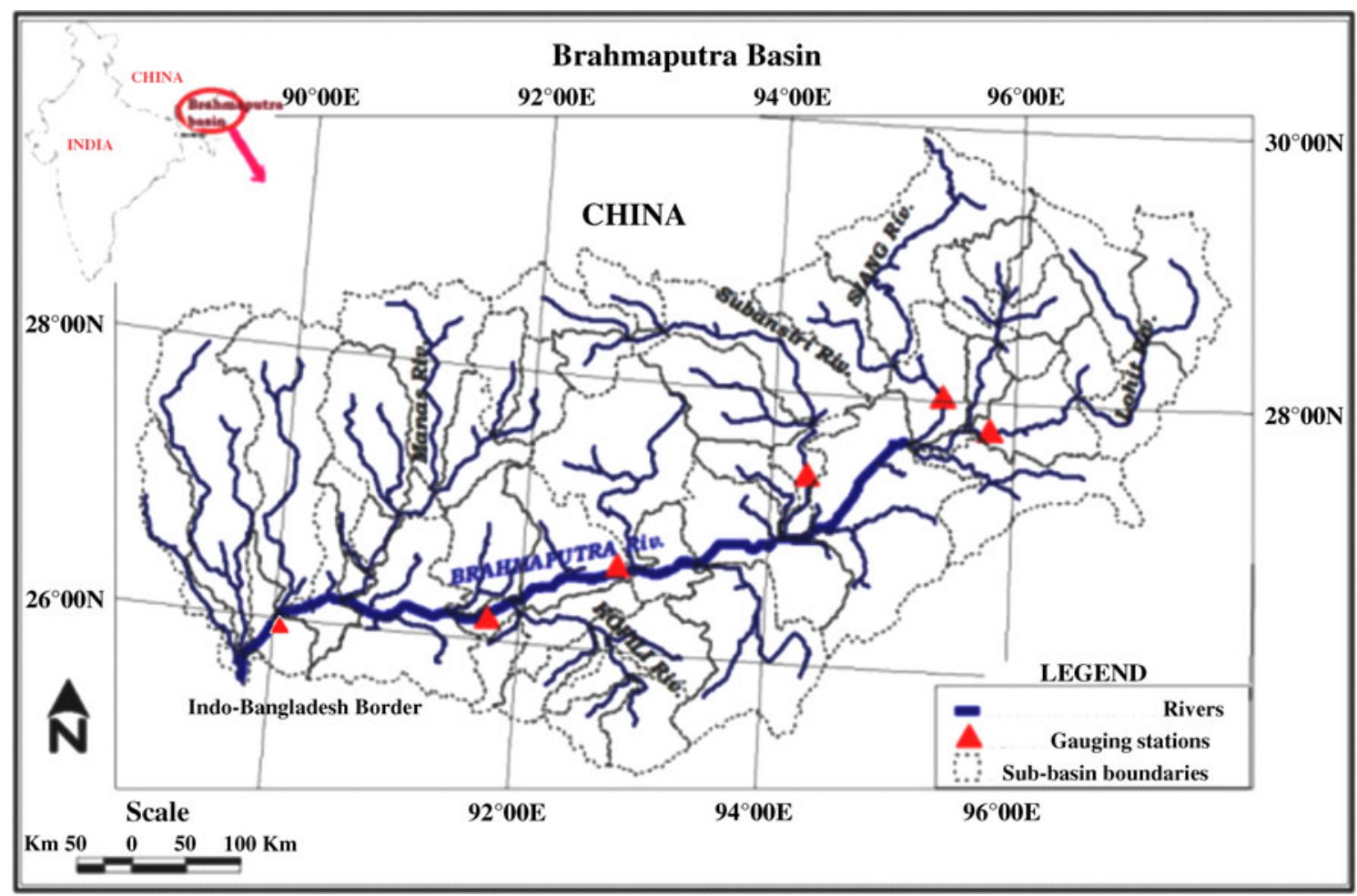

Figure 1. Brahmaputra river basin with its drainage network and gauging stations. 
$300 \mathrm{~mm}$ /day have been observed annually during 1993-2001 (Soja and Starkel 2007).

Temporal variation of the basin average rainfall of two tributaries and for the whole basin is shown in figure 2. Different distinct rainfall spells can be observed during the pre-monsoon and monsoonal season. Overall, $66-85 \%$ of the annual rainfall occurs during the monsoon and $20-30 \%$ occurs during the pre-monsoon season, while a very small percentage of the annual rainfall occurs in winter (Sarma 2005).

\subsection{Hydrology and flood characteristics}

In this basin, there are seven major land use/land cover classes such as snow cover, hilly grass land areas/ jhum cultivation, forest, paddy agriculture, non-paddy agriculture (rain fed cropland), wetland and homestead/built-up area. For rainfall-induced floods, runoff generation from hillslopes with vegetation cover in forest, paddy fields and grass lands primarily dominates in the region. These hillslopes with vegetation cover generally have deep and permeable topsoil with an impermeable layer at a shallow depth (Vadivelu et al 2004) and causes fast hydrological response in the form of subsurface storm flow (Sarkar et al 2008).

As mentioned earlier, intense monsoonal rainfall spells frequently occur over the basin during the pre-monsoon and monsoon seasons. These intense spells of rainfall cause fast hydrological response in the form of flood waves. Due to its large contributing area with dense drainage network, the flood wave prevails for a longer duration with significant flood lift. As a result, the specific flood discharge of the Brahmaputra is the highest in the world. At the gauging site of Bahadurabad in Bangladesh it is reported to be about $0.149 \mathrm{~m}^{3} / \mathrm{s}$ per $\mathrm{km}^{2}$ (Datta and Singh 2004).

A typical stage hydrograph of the river Brahmaputra at the gauging station of Guwahati during a monsoon period is depicted in figure 3 . In this hydrograph, seven distinct flood waves can be noticed. The hydrograph characteristics are found to be similar over the observed years, and can be separated into two components, namely, flood waves and monsoonal response. The flood waves are found to be the fast hydrological response caused by the clustered rainfall spells in the river basin. The other component is the average response of the monsoonal rainfall distribution. From such a typical hydrograph, flood wave characteristics such as duration of the individual flood events $\left(T_{d}\right)$, arrival time of the waves $\left(T_{i}\right)$, time to peak $\left(T_{p}\right)$ and maximum flood lift can be estimated using the time series of discharge data. A detailed procedure to extract those characteristics is available in Karmaker and Dutta (2010) and used in the present study.

On an average, the Brahmaputra experiences four to five major flood waves, in addition to the normal monsoonal response, annually during the monsoon months (Datta and Singh 2004; Karmaker and Dutta 2010). During these flood waves, flood lift at Guwahati is recorded as high as $9.91 \mathrm{~m}$ (Datta and Singh 2004). Also, some of the tributaries gets congested during these high flow periods.

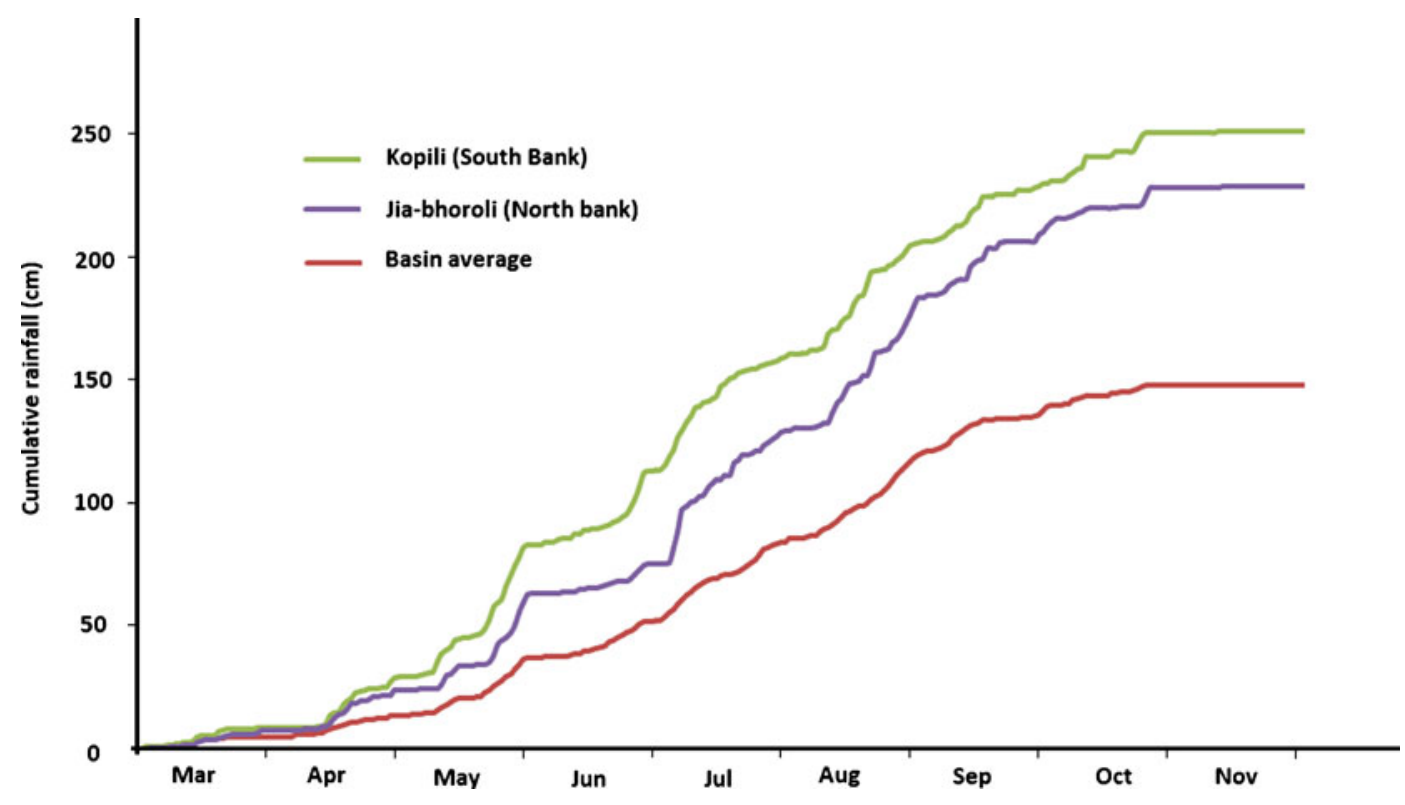

Figure 2. Cumulative rainfall depth $(\mathrm{cm})$ in the Brahmaputra river basin and its two tributary basins in 1988 . 


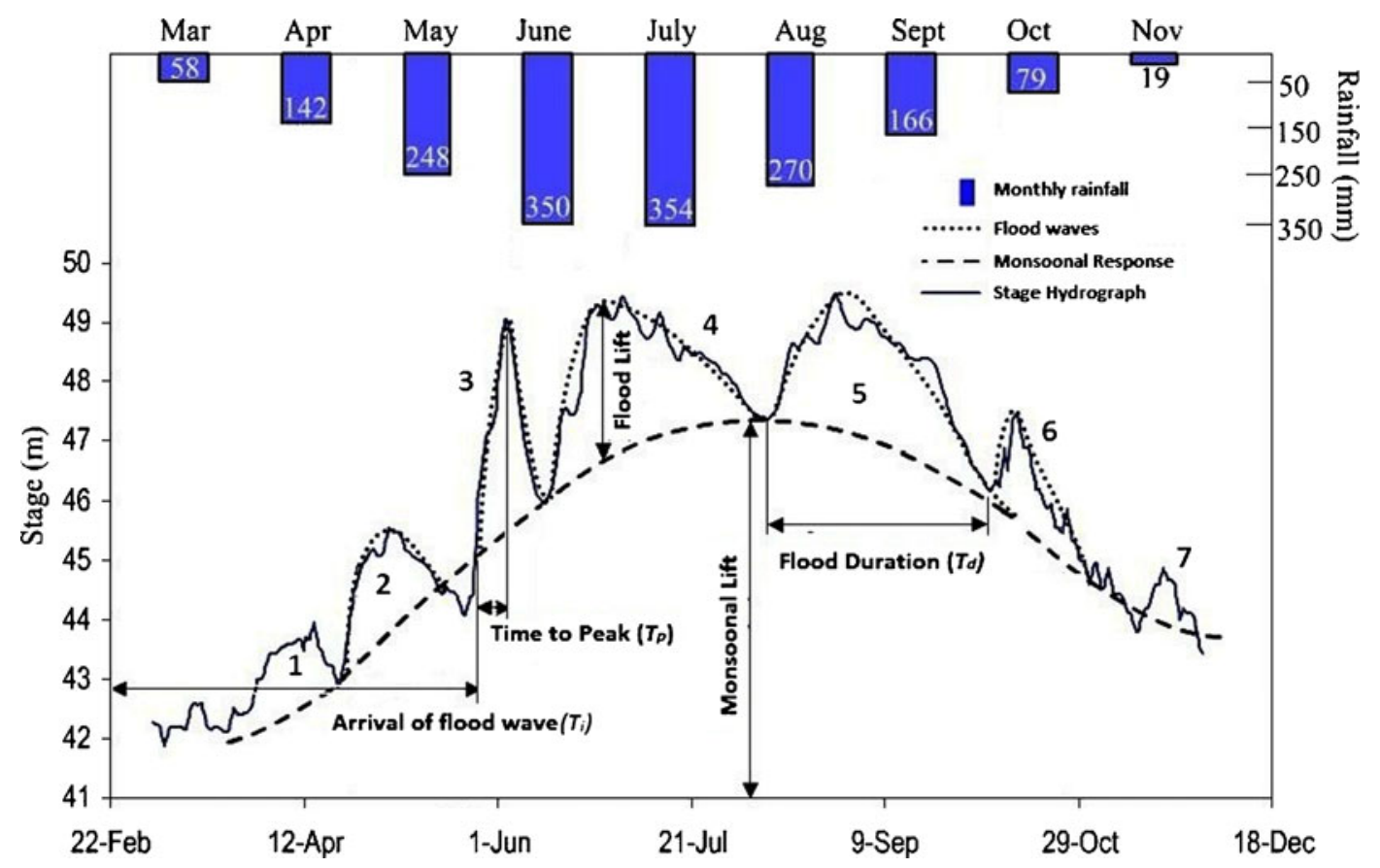

Figure 3. Illustrative diagram showing different characteristics of flood waves.

\section{Methodology}

\subsection{Model description}

Rice Irrigation System Evaluation (RISE) model (Dutta and Zade 2003) is a distributed physically based hydrological model in which surface and subsurface hydrologic processes have been conceptualized for a watershed in tropical/subtropical regions. This model defines the dominant hydrological processes based on different distinct hydrological similarity classes (HSC). For the present study, four distinct HSCs were delineated based on seven distinct type of soil classes and seven landuse/land-cover types. The four delineated classes are (i) Macropore dominated vegetated hillslope (HSC-1), (ii) Paddy cultivation dominated agricultural lands (HSC-2), (iii) Semi-impervious urban areas (HSC-3) and (iv) Wetlands and permanent sinks (HSC-4). For each class, runoff generation processes have been conceptualized as depicted in figure 4. Macropore-dominated processes have been conceptualized for HSC-1, while retention excess flow and Hortonian infiltration excess overland flow have been conceptualized for HSC-2 and HSC-3 respectively. Water budgeting has been done for HSC-4. Subsurface storm flow processes are mathematically inter-coupled with infiltration processes. Lateral flow to the channel segment has been conceptualized following the steepest gradient method, while the linearized channel routing process follows the kinematic wave approximation approach. A detailed mathematical formulation of each hydrological processes used in the model can be obtained from Mishra et al (2008).

\subsection{Input data and model parameters}

The details of the input data and parameters used in the model are listed in table 1. The topographic information has been obtained from Hydro1K dataset for Asia provided by USGS (http:// eros.usgs.gov/\#/Find_Data/Products_and_Data_ Available/gtopo30/hydro). The dataset consisting of elevation, compound topographic index (CTI), slope, aspect, flow-direction, flow accumulation, drainage basins and stream network data having a spatial resolution of $1000 \mathrm{~m}$ was downloaded and processed using a Geographic Information System (GIS) software.

In order to define the physical processes occurring in various parts of the basin, hydrological similarity classes (HSC) have been delineated. Global land use/land cover data from 'European Space Agency-Ionia Glob Cover Portal' has been used for this purpose (http://ionia1.esrin.esa.int/). This dataset has the spatial resolution of $300 \mathrm{~m}$ and independently validated, derived from an automatic and regionally tuned classification of a time series of MERIS-FR composites, for the period December 2004 to June 2006 (Source data: (C) ESA/ ESA GlobCover Project, led by MEDIAS-France; Image: (c) ESA/ESA GlobCover Project, led by MEDIAS-France). The land cover types were regrouped into seven land use/land cover classes which have been spatially overlapped with the soil 


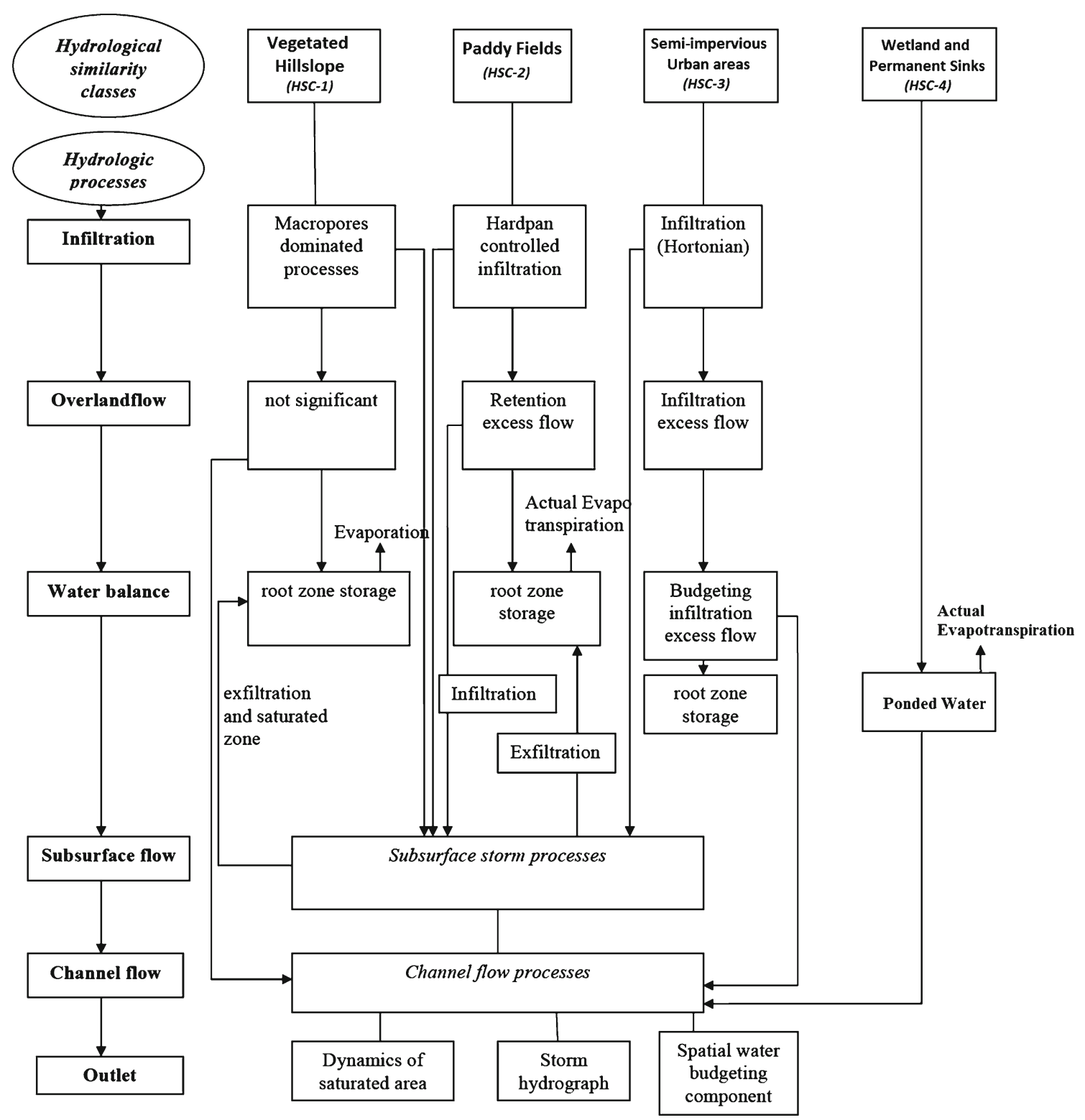

Figure 4. Conceptual diagram of the macro-scale hydrological model showing different hydrological processes and their inter-coupled relationship.

and topography data to delineate four HSC. The classes were resampled to the grid size of $1000 \mathrm{~m}$ used in the simulation. The land use/land cover distribution over the basin has been assumed to be static over the years since the effect of changing land use/land cover on the flood vulnerability of the Brahmaputra basin was found to be inconsequential compared to the effect of other parameters like climate variability (Ghosh and Dutta 2010).

Soil maps of 1:500,000 scale obtained from National Bureau of Soil Survey and Land Use Planning (NBSS\&LUP, India) have been used to generate the soil distribution zones within the basin. Daily rainfall and temperature data averaged over an area of spatial resolution of one degree, obtained from Indian Meteorological Department (IMD), has been used for the calibration and validation of the model for the observed dataset between 1978 and 2003.

For all the simulations a uniform grid size of $1000 \mathrm{~m}$ and a simulation time step of $24 \mathrm{~h}$ were adopted. However, any convenient grid size can be adopted for the model simulations - finer grid sizes increase the computational time considerably. The time resolution of $24 \mathrm{~h}$ has been found to be sufficient for capturing time scales of important flood characteristics, such as time of peak flow (average 7 days), duration of the flood waves (average 15 days), etc. In order to eliminate the possible deviations due to the initial conditions, the simulation was started well before the pre-monsoonal season. 
Table 1. Input data, model parameters and their sources.

\begin{tabular}{lll}
\hline Parameter/data type & \multicolumn{1}{c}{ Name } & Data source \\
\hline Static & Topography and basin characteristics & Hydro1k database, USGS \\
& Soil type distribution & NBSS \& LUP, India \\
& Soil parameters & NBSS \& LUP, India \\
& Land use classes & Ionia Glob Cover Portal, ESA \\
& Average surface storage in paddy field $(h)$ & Calibration parameter \\
& Degree of impermeability of hardpan formation $(r)$ & Calibration parameter \\
& Minimum storing depth in macropores & Calibration parameter \\
& Exponential transmissivity decay function $(m)$ & Calibration parameter \\
Time-variant & Natural logarithm of transmissivity of just saturated & Calibration parameter \\
& soil profile (ln $\left.T_{0}\right)$ & \\
& Initial saturated topographic index $(T I)$ & Hydro1k database, USGS \\
& Variable advection, diffusion constants $(a, b, \alpha, \beta)$ & Computed model parameters \\
& Daily observed stage data & State Water Resources Department, \\
& & Assam, India \\
& Rainfall and temperature data (Validation period) & IMD, Pune, India \\
& Future rainfall and temperature data & IITM, Pune, India \\
\hline
\end{tabular}

\subsection{Climate change and the projected scenario}

Application of a regional climate modelling system, known as PRECIS (Providing Regional Climates for Impacts Studies) developed by the Hadley Centre for Climate Prediction and Research, was carried out for A2 scenario (SRES-98 emission scenarios after IPCC) in India to develop highresolution climate change scenarios (Rupa Kumar et al 2006). PRECIS was forced at its lateral boundaries by the simulations of a high-resolution global model (HadAM3H) with a horizontal resolution of $150 \times 150 \mathrm{~km}$, in the so-called time slice experiments. The baseline simulation (1961-1990) with PRECIS was evaluated based on the observed data, including an examination of the impact of enhanced resolution and an identification of biases (Rupa Kumar et al 2006). PRECIS simulation for 2071-2100 indicates an all-round warming over the Indian subcontinent, associated with increasing greenhouse gas concentrations. The results of this PRECIS simulation output dataset with a spatial resolution of $0.44^{\circ} \times 0.44^{\circ}$ have been used for the present study.

In recent times the PRECIS simulation output has been used as input for hydrological models to evaluate the impact of climate change on the water resources of hilly areas (Akhtar et al 2008, 2009) and tropical areas (Buytaert et al 2010). In those studies it was found that the hydrological model calibrated with the PRECIS output performed better than other climatic simulations used in that study (Akhtar et al 2009). In the tropical region of the Amazon basin, PRECIS has been found to simulate the total rainfall better than GCMs used in that study (Buytaert et al 2010).
For the present study PRECIS simulation over the Brahmaputra basin has been evaluated by comparing the observed rainfall/temperature data with the simulated one. The comparison study shows that PRECIS output overestimates the seasonal rainfall by about $12.4 \%$ for the whole study area during the baseline simulation. Future projection of the rainfall distribution by PRECIS indicates higher increments in pre-monsoonal rainfall than the late monsoonal rainfall (figure 5). Before using the PRECIS simulation, data seasonwise scaling factors, to achieve the same mean seasonal rainfall for the observed data and the PRECIS simulation data for the base period, have been derived for each rainfall grid independently. The estimated scaling factors for each grid have been used to scale the future projected daily rainfall data to be used in the hydrological model. This has been carried

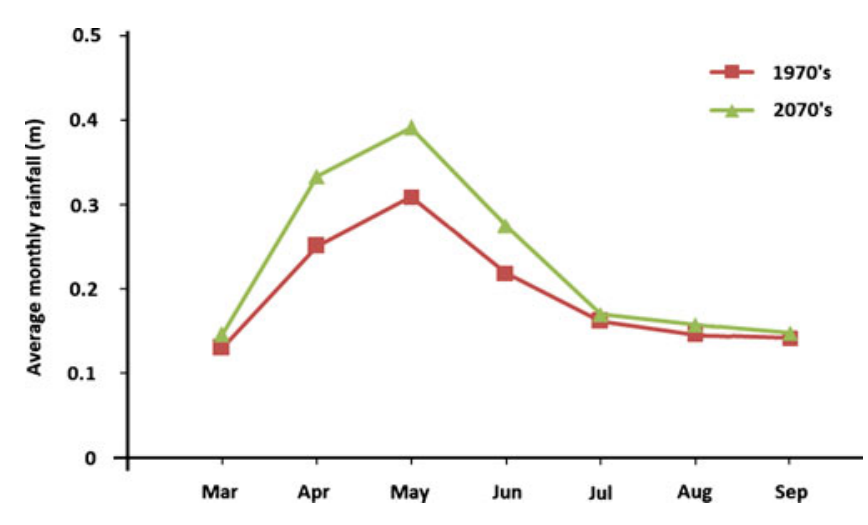

Figure 5. Basin average monthly total rainfall prediction by PRECIS simulation for the base period (1961-1990) and for the future projected period (1971-2100). 


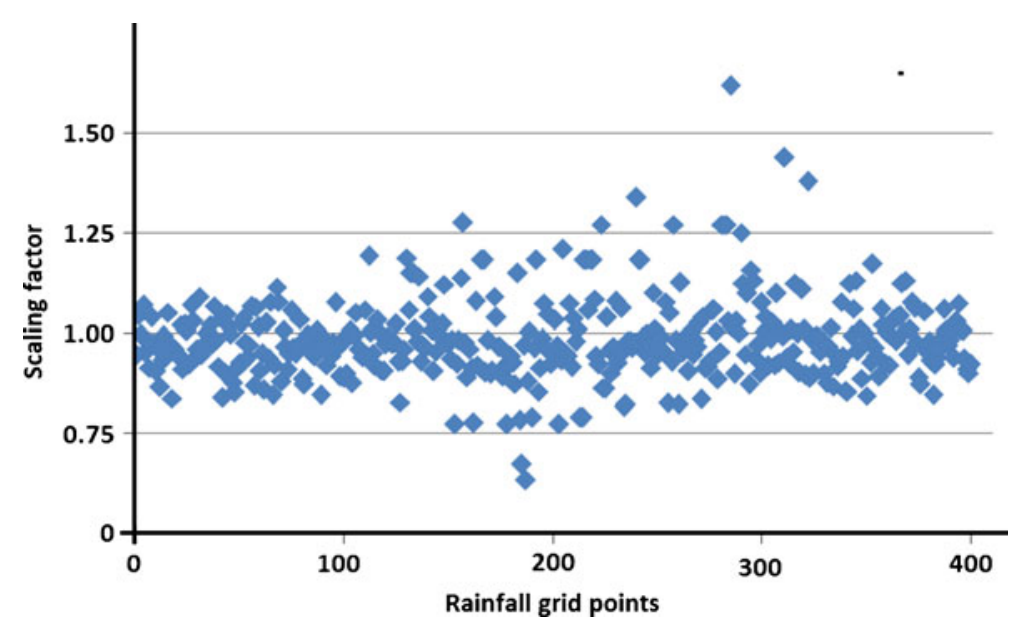

Figure 6. Seasonal scaling factor for the monsoonal season (June-Sept) for all the rainfall grids.

out to preserve the temporal variability of the climatic simulation and to incorporate more direct representations of climatic simulations into the hydrological model (Graham et al 2007). The scaling factors for the monsoon season of all the grids over the study area are presented in figure 6 . The range of variation of the scaling factors has been found to be between 0.75 and 1.5. The same scaling process has been carried out for the temperature also. The scale factors for temperature have been found to be in the range of $0.42-1.81$. In general at higher altitudes these biases are found to be more. While the scaling factors for monsoonal rainfall ranges from 0.82 to 1.38 for the valley part of the basin, the same has been found to be in the range of $0.75-1.5$ for the hilly region of the basin.

\section{Results and discussion}

\subsection{Model calibration}

Five model calibration parameters have been adjusted manually for the river basin. The monsoon season of the year 1988 was considered as the calibration period. The available daily stage records in Guwahati and Tezpur of the
Brahmaputra reach have been used for this purpose. By conducting a set of trial simulations and comparisons between observed stage hydrograph and simulated discharge hydrograph, the calibration parameters have been adjusted to match the flood characteristics as closely as possible. The calibration parameters, their range and calibrated values are given in table 2 .

Figure 7 shows the observed stage hydrograph at the Guwahati gauging station compared with simulated discharge $\left(Q_{s}\right)$ hydrograph. From this figure it can be observed that the flood waves have been predicted accurately in terms of arrival of the wave, flood duration and time to peak. Interestingly, there was a multiple peak flood wave in August and this is also reflected in the simulation result. This means that the model is able to predict the behaviour of this multiple peak flood wave also. In the Tezpur gauging station, similar flood wave pattern has also been observed and model prediction has been found to be close to the observed flood wave characteristics. More detailed comparison statistics of these predictions based on each flood characteristics are discussed in section 4.2.

In a highly braided river system like Brahmaputra, measurement of discharge is possible at only a few nodal points (constraints) such as Tezpur and Guwahati. At the nodal reaches

Table 2. Calibration parameters, their range and calibrated value.

\begin{tabular}{llc}
\hline Calibration parameters & $\begin{array}{c}\text { Calibrated } \\
\text { value }\end{array}$ & Range \\
\hline Average surface storage in paddy field $\left(h_{r e t}\right)$ & $0.3 \mathrm{~m}$ & $0-0.5 \mathrm{~m}$ \\
Degree of impermeability of hardpan formation $(r)$ & 1000 & $700-2000$ \\
Maximum storing depth in macropores $\left(S_{\max }\right)$ & $0.1 \mathrm{~m}$ & $0.03-0.9 \mathrm{~m}$ \\
Exponential transmissivity decay function $(m)$ & 0.035 & $0.002-0.05$ \\
Natural logarithm of transmissivity of just saturated soil $\left(\ln T_{0}\right)$ & 0.01 & $0-1.6$ \\
\hline
\end{tabular}




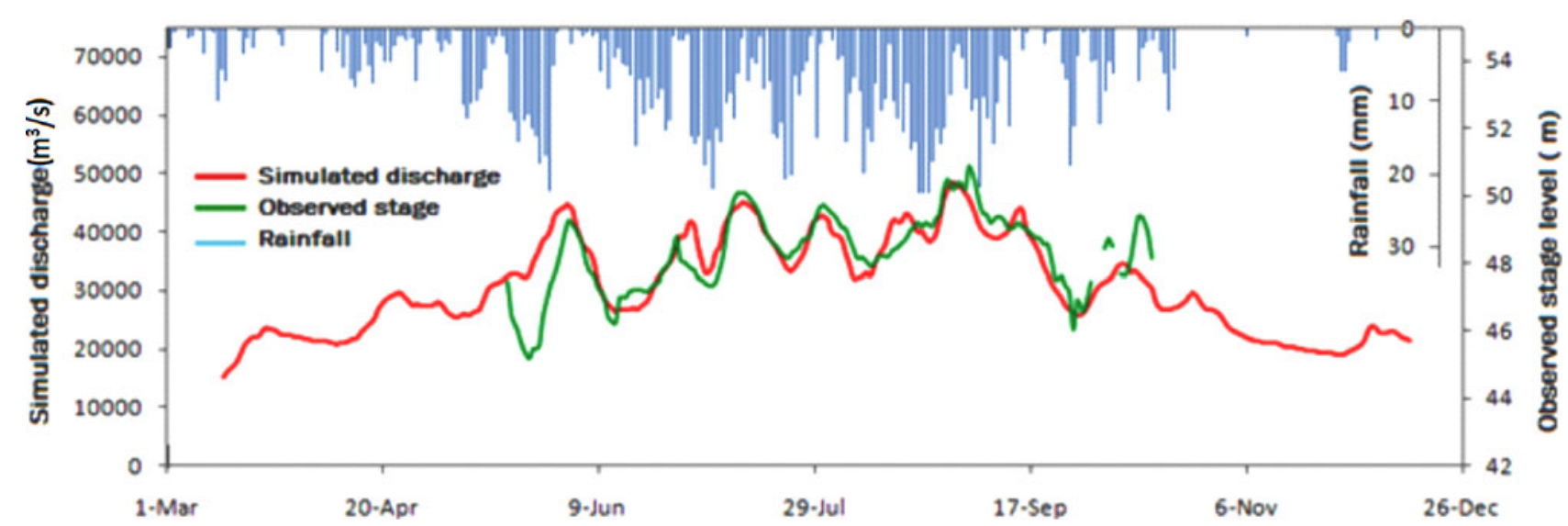

Figure 7. Simulated discharge and observed stage hydrographs at the Guwahati gauging station with basin averaged daily rainfall for the year 1988 .

also, the bed level of the river generally undergoes aggradation/degradation throughout the year. Therefore, it is necessary to have regular updates of the rating curve or the use of advanced river survey instruments such as Acoustic Doppler Current Profiler (ADCP) to obtain the time series of discharge data over the years. But these types of advanced measurement systems have not been implemented so far in these locations.

However, in order to compare the peak discharge, the available rating curve for the year 1992 for the gauging station of Guwahati has been used. Comparison between the simulated discharge and observed discharge values is presented in figure 8. From the figure it can be seen that the peak discharges during the highest flood lifts closely agree with the observed discharge of greater than $35,000 \mathrm{~m}^{3} / \mathrm{s}$. However, the model overpredicts in the medium discharge ranges $(15,000$ $\left.30,000 \mathrm{~m}^{3} / \mathrm{s}\right)$, which is reasonably acceptable for a large river basin like Brahmaputra.

\subsection{Model validation}

Another eight wet years from the gauge record of 25 years period from 1978 to 2003 were chosen for validation of the model. The selection was done on the basis of statistical analysis of the lift of the flood waves (Karmaker and Dutta 2010). The chosen years had the maximum flood lift among the observed years. Note that among the selected years, 1991 had the highest flood peak and 1992 had the lowest. Analysis of the flood wave characteristics of

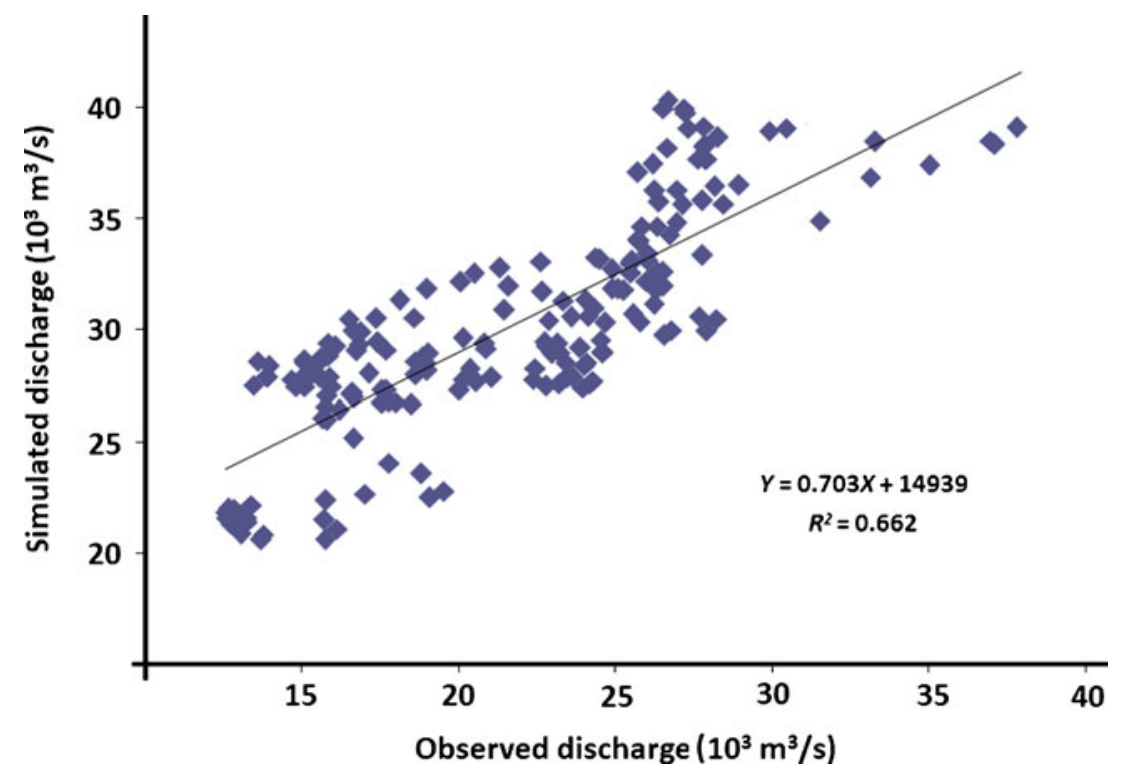

Figure 8. Correlation between simulated discharge and observed discharge at the Guwahati gauging station for the year 1992. 


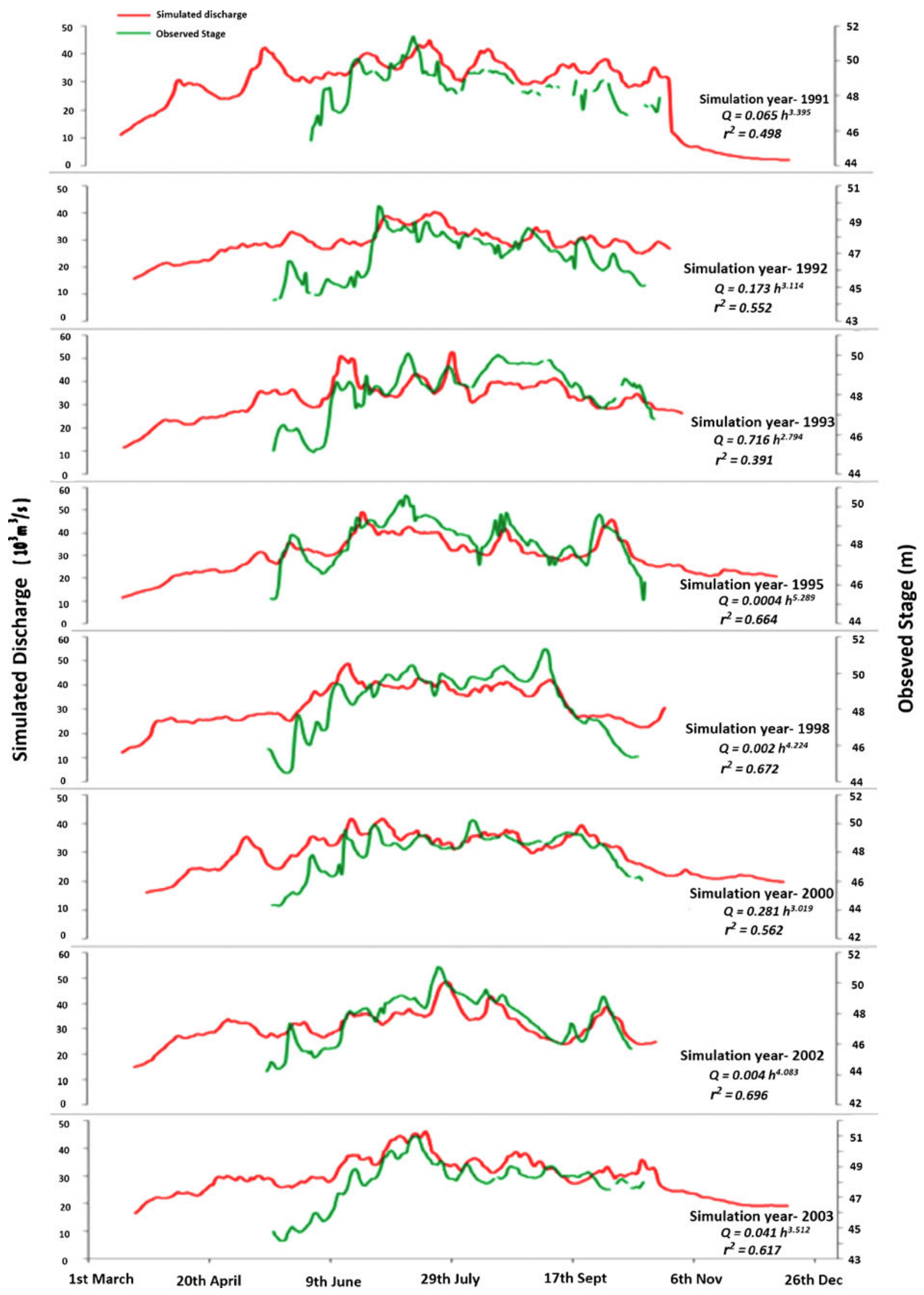

Figure 9. Observed stage hydrograph and the simulated discharge hydrograph, at the gauging station of Guwahati $(Q=$ simulated discharge; $h=$ observed stage). 
Table 3. Prediction accuracy for the flood wave characteristics.

\begin{tabular}{lccccc}
\hline Wave & \multicolumn{5}{c}{ No. of flood waves } \\
\cline { 2 - 5 } characteristics & $T_{d n}<1$ & $1 \leq T_{d n}<2$ & $2 \leq T_{d n}<3$ & $3 \leq T_{d n}<4$ & $4 \leq T_{d n}<5$ \\
\hline Arrival time $\left(T_{i}\right)$ & $33(70.2 \%)$ & 9 & 4 & 1 & - \\
Time to peak $\left(T_{p}\right)$ & $17(36.2 \%)$ & 11 & 11 & 7 & 1 \\
Flood duration $\left(T_{d}\right)$ & $25(53.2 \%)$ & 13 & 8 & 1 & 47 \\
\hline
\end{tabular}

$T_{d n}=$ Time difference between the simulated and the observed flood wave characteristics (days).

Table 4. Peak discharge prediction in the tributaries of Brahmaputra by regional formula and RISE simulation.

\begin{tabular}{|c|c|c|c|c|c|c|c|c|c|c|c|c|c|c|}
\hline \multirow[b]{2}{*}{ River } & \multicolumn{4}{|c|}{$\begin{array}{l}\text { Annual peak discharge } \\
\text { (regional analysis; } \mathrm{m}^{3} / \mathrm{s} \text { ) } \\
\text { Return period (years) }\end{array}$} & \multicolumn{10}{|c|}{ Annual peak discharge (simulated; $\mathrm{m}^{3} / \mathrm{s}$ ) } \\
\hline & 2 & 5 & 10 & 25 & 1988 & 1991 & 1992 & 1993 & 1995 & 1998 & 2000 & 2002 & 2003 & Average \\
\hline Manas & 7008 & 9747 & 11604 & 14000 & 11618 & 8711 & 9210 & 11971 & 11836 & 8830 & 10217 & 11981 & 9139 & 10390 \\
\hline Jia Bhoroli & 3292 & 4579 & 5451 & 6577 & 10985 & 11462 & 7792 & 11663 & 13060 & 11148 & 9964 & 11006 & 11715 & 10977 \\
\hline Subansiri & 6097 & 8480 & 10095 & 12179 & 9849 & 8347 & 8029 & 10424 & 11697 & 10858 & 9148 & 9352 & 9395 & 9677 \\
\hline
\end{tabular}

the simulated result have been carried out for the years 1991, 1992, 1993, 1995, 1998, 2000, 2002 and 2003. Figure 9 shows the comparison of simulated and observed hydrographs showing the flood waves distinctly.

The difference in terms of number of days between the simulated and the observed flood wave characteristics $\left(T_{d n}\right)$ have been analysed for the 47 flood waves that occurred in the chosen wet years. Table 3 represents the prediction accuracy of arrival time of flood waves $\left(T_{i}\right)$, time to peak $\left(T_{p}\right)$ and the flood duration $\left(T_{d}\right)$ of the wave. From the table it can be observed that arrival time of the flood waves has been predicted with no difference in about $70.2 \%$ cases and within 1 day difference for about $89.4 \%$ cases. Similarly, the time to peak has $36.2 \% ; 59.6 \%$ and $82.9 \%$ prediction within 0 day, 1 day and 2 day accuracy respectively. Also, the flood duration has been predicted for 0 day and 1 day of accuracy for $53.2 \%$ and $80.8 \%$ cases respectively.

It can be noted that as the stage level is being recorded at an interval of $24 \mathrm{~h}$, the observed data itself may have a biasness of \pm 1 day. The distribution of lag and lead between the simulated and observed flood wave characteristics has been found to be almost equally distributed. For example, the arrival time of flood waves with 1 lag day difference is about $57 \%$ of total flood waves and 1 day lead predication for about $43 \%$ cases. As reported elsewhere (Datta and Singh 2004), the average travel period of the flood waves from the foothills of the Himalayas to Indo-Bangladesh border is 5.3 days. Therefore, considering this travel time and the possible bias in the observed time series data, the model prediction is fairly acceptable for the flood characteristics such as arrival time of the flood wave, time of peak flow (average 7 days) and duration of the flood (average 15 days).

In the absence of the updated rating curve, simulated discharge has been correlated with the observed stage level using a pseudo-rating curve consisting of a power function for each year separately. The function parameters and the values of the correlation coefficients have been found to vary annually as it is expected and the variation of correlation coefficients ranges from 0.391 to 0.696 and are presented in figure 9 .

\subsection{Model performance analysis at tributary level}

In order to evaluate the performance of the model at the tributary level, simulated discharges have been analysed for three major tributaries. Among the tributaries, Subansiri, Jia Bhoroli and Manas rivers were considered as these three northern tributaries as these have catchment area of more than $10,000 \mathrm{~km}^{2}$. Table 4 shows the simulated annual peak discharges of these tributaries. In order to compare the range of simulated discharges, the discharges of different return period by a regional analysis model (Kumar and Chatterjee 2005) were considered. For Subansiri river, the average peak discharge predicted for the selected highest flood lift years is about $9677 \mathrm{~m}^{3} / \mathrm{s}$, which is within the range of the regional model prediction. Similar statistical comparison can be seen for Manas river also. However, overprediction of peak discharge can be observed for Jia Bhoroli river. This may have 
several resons including the chances of failure of the regional analysis model for a unique rainfallrunoff response system of a medium-sized catchment. Therefore, the model has been found to predict the variation of annual peak discharge in the tributary level also.

\subsection{Model performance with PRECIS climate data}

Hydrological model simulation, using the bias corrected PRECIS data, has been done for the year 1988. The simulation result at the basin scale has been compared with the simulation result using the observed meteorological data and presented in figure 10. For the year 1988, seasonal total rainfall over the basin has been found to be underestimated by $9.7 \%$ in the bias-corrected PRECIS simulation data. The hydrological model simulation using this bias-corrected PRECIS data underestimated total seasonal discharge by $9.4 \%$ as compared with the hydrological simulation using the observed data for that year. At the basin outlet, the peak discharge has been underestimated by $5.3 \%$ with the input of PRECIS meteorological data to the hydrological model.

\subsection{Effect of climate change on annual peak discharge}

Figure 11 summarizes the changes in annual peak discharges between the base period (1961-1990) and the future projected period (2071-2100). Comparison of 30 years of simulation results gives a consistent indication that all the peak monsoonal flow quantiles would increase by 2070s compared to the baseline period of 1970s. The increase in the median value of monsoonal peak flow series has been found to be $7.5 \%$ at Tezpur. This change in the quantiles of the peak discharges has been found to be increasing towards the downstream. At the gauging station of Guwahati, increase in the median value of the monsoonal peak flow series has been found to be $19.3 \%$, and at Dhubri in the lower reach of the river Brahmaputra, this increment has been found to be $21 \%$. So, this clearly indicates that the flood vulnerability due to monsoonal floods would increase to the downstream of the river by the end of this century.

A similar trend analysis has been carried out for the pre-monsoonal flood waves. As illustrated in figure 11, at the upper part of the river Brahmaputra, the Tezpur gauging site might experience an increment of $11.7 \%$ in the median value of pre-monsoonal peak discharge series. This increasing trend at the gauging site of Guwahati and Dhubri has been found to be $27.8 \%$ and $27.7 \%$ respectively. This finding indicates, in terms of flood risks and damages due to pre-monsoonal flood waves, the middle and lower reaches of the river Brahmaputra would be more vulnerable than the upper part. Apart from these changes in median value of peak discharge series, greater variation in peak discharges has also been predicted in all three gauging stations.

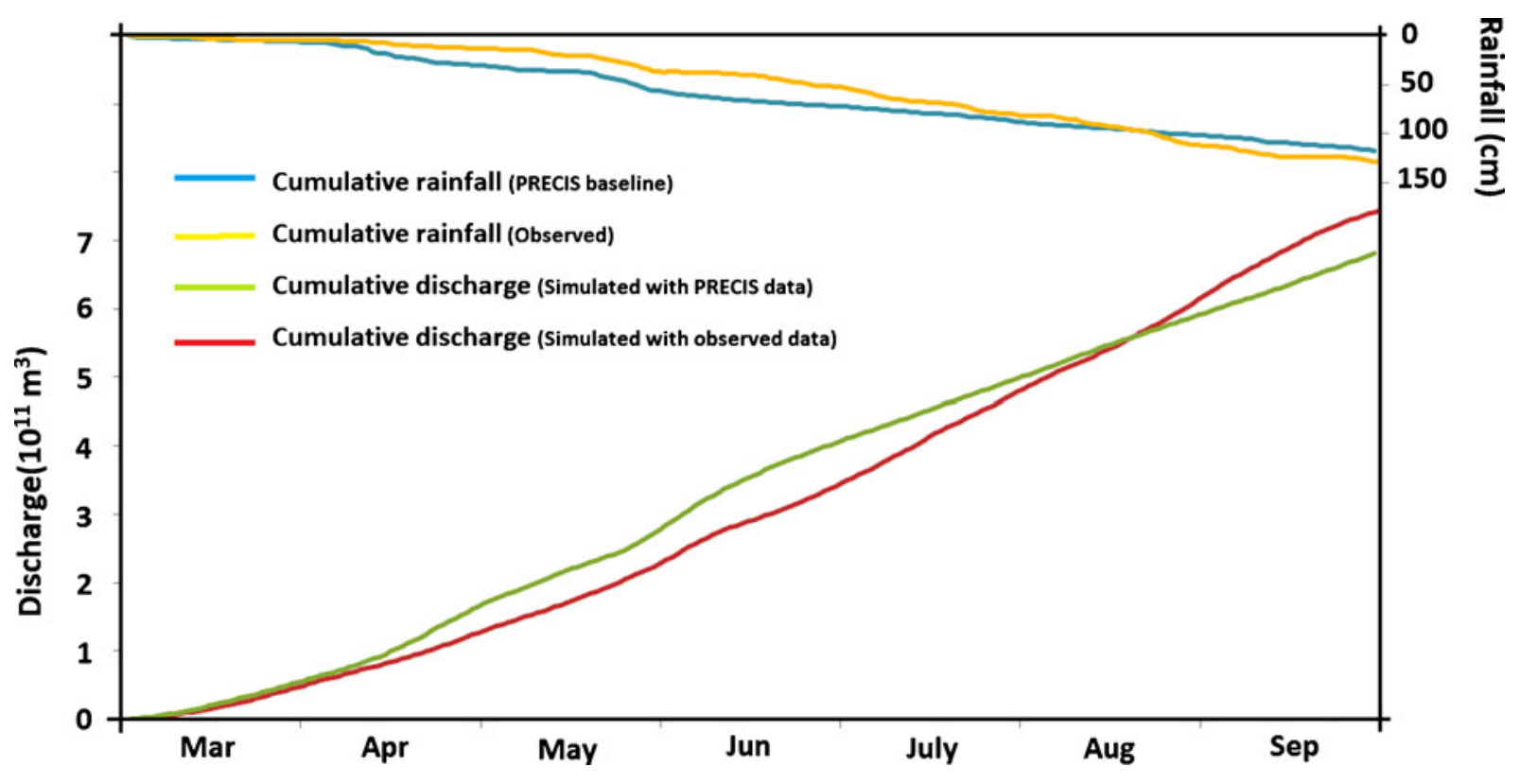

Figure 10. Comparison of the observed cumulative rainfall and bias corrected cumulative rainfall data from PRECIS output at the basin scale; the cumulative discharges at basin level predicted by the hydrological model using these two input data for the year 1988 . 


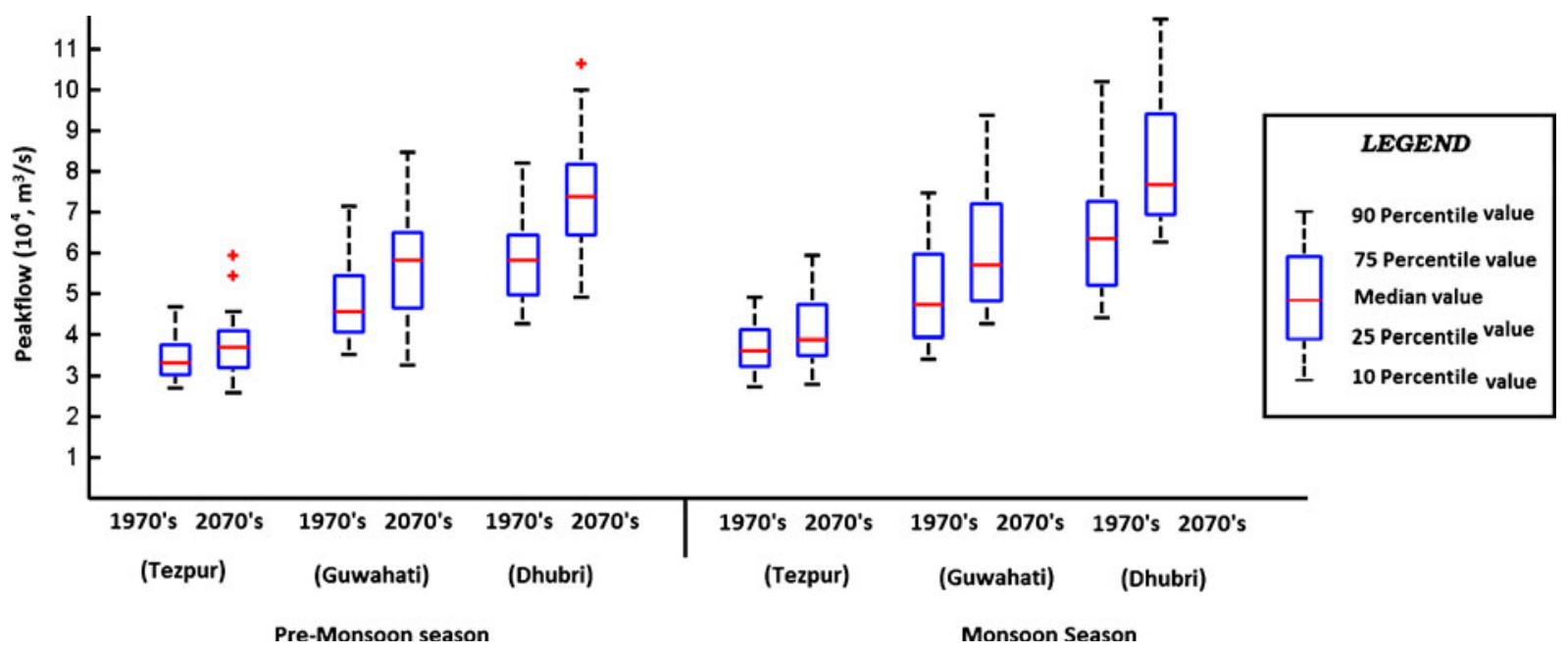

Figure 11. Changes in peak discharge series of the Brahmaputra river at three gauging stations for two different seasons.

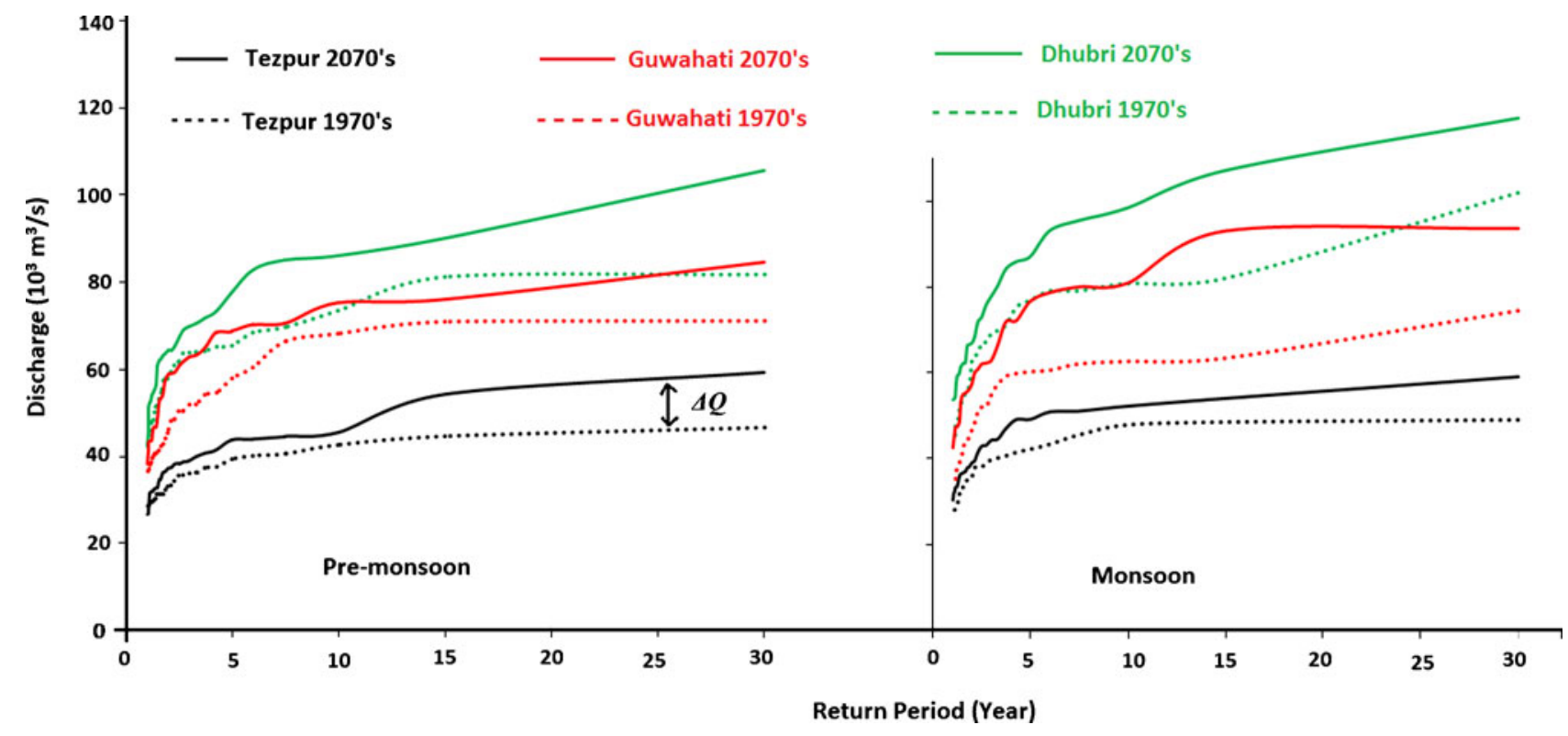

Figure 12. Relationship of the changes in the peak discharges and return period of the events for pre-monsoonal and monsoonal seasons for three gauging stations.

In general, pre-monsoonal flood waves have shown a larger increment in terms of percent changes in the peak flow than the monsoonal flood waves. However, monsoonal flood waves can cause greater catastrophic disaster within the valley part due to higher volume of the flood wave discharge. Hence, the changes in monsoonal peak discharges are of greater concern for flood management in the basin.

\subsection{Effect of climate change on the frequency of annual peak discharge}

Return period analysis of the 30 years simulation result has been carried out for both the base period and the future projected period to estimate the changes of the most frequent events for both pre-monsoon and monsoon flood waves. Figure 12 shows the peak discharges with their return periods for three gauging stations for two different seasons. This figure indicates that there is significant increase in peak discharge for the events of higher return period and it progressively increases towards the downstream of the river. The changes in the magnitude of the monsoonal peak discharges can be correlated to their corresponding return period. This correlation can be articulated as a logarithmic relationship between the changes in the peak discharge and its return period, and can be 


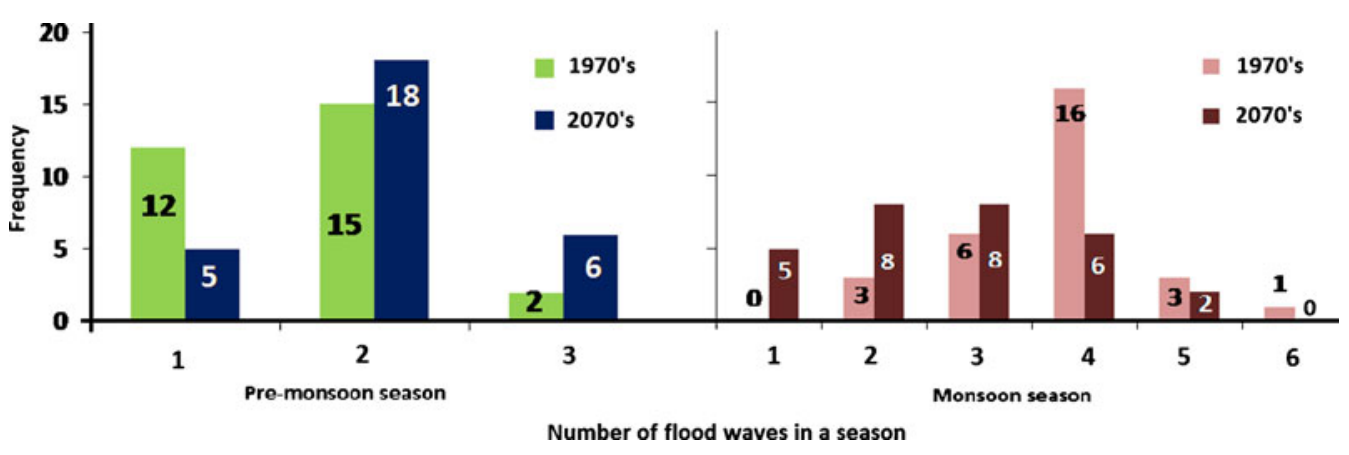

Figure 13. Changes in the frequency of flood waves per year for three gauging stations for two different seasons.

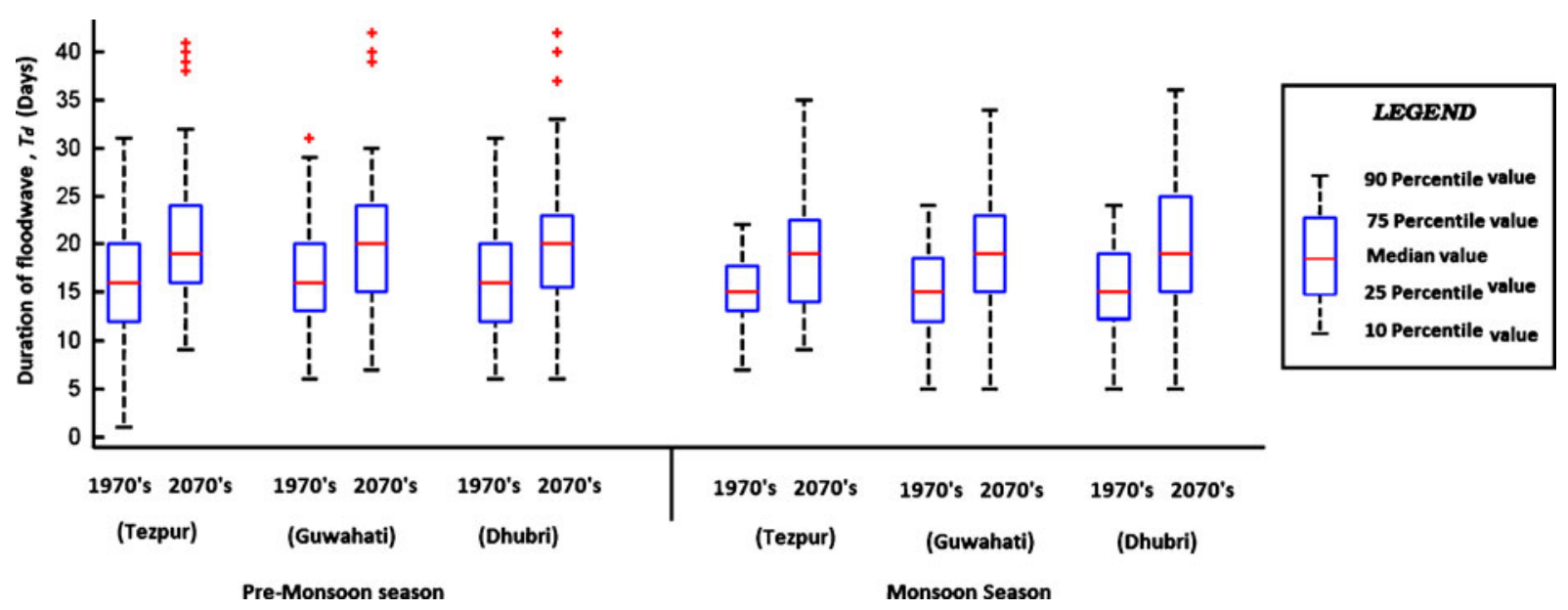

Figure 14. Changes in the duration of the flood waves for three gauging stations for two different seasons.

mathematically expressed in the following equation as:

$$
\Delta Q=A \ln (T)+B
$$

where $\Delta Q$ is the change in the annual peak discharge for an event of a return period of $T$ years. $A$ and $B$ are constants to be estimated locally for the corresponding river gauging station. In the present study, the value of $A$ has been estimated to be 1644, 4193 and 4031 for Tezpur, Guwahati and Dhubri, respectively, and the value of $B$ has been estimated to be 2949, 8566 and 6354 for the same river gauging stations respectively. The higher constant $(A, B)$ values indicate increased flood vulnerability due to floods in the future.

However, the changes in the magnitude of the pre-monsoonal peak discharges have been found to be rather abrupt and no significant correlation between the peak discharges and their corresponding return periods have been observed, although from the figure it can be observed that the extreme events of return period more than 15 years and the most frequent events have shown greater changes than the events of return period between 5 and 10 years.

\subsection{Effect of climate change on the characteristics of the flood waves}

Analysis of flood wave characteristics has been carried out to determine the changes in the frequency of flood waves and their characteristics under the projected climate change scenario. In figure 13, the frequency of the flood waves from the 30 years simulation result both for baseline period and future projected period is depicted for premonsoon and monsoon seasons. From the figure it can be observed that, while the number of flood waves per year has increased from 1-2 flood waves to 2-3 flood waves per year for the pre-monsoonal period, the same has decreased for the monsoonal period from an average of 3-4 flood waves to 2-4 flood waves per year. Another important observation noted here is that most of the flood waves in the river Brahmaputra are generated in the upland 


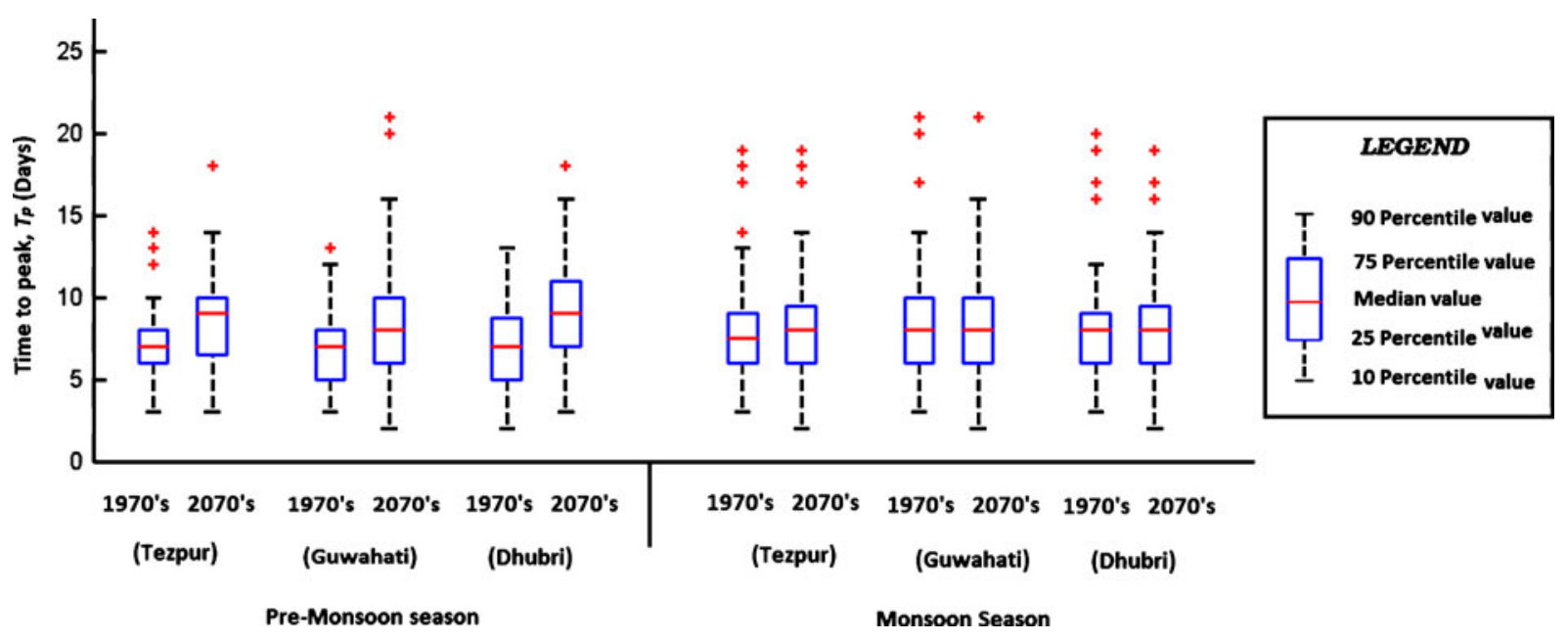

Figure 15. Changes in the time to peak of the flood waves for three gauging stations for two different seasons.

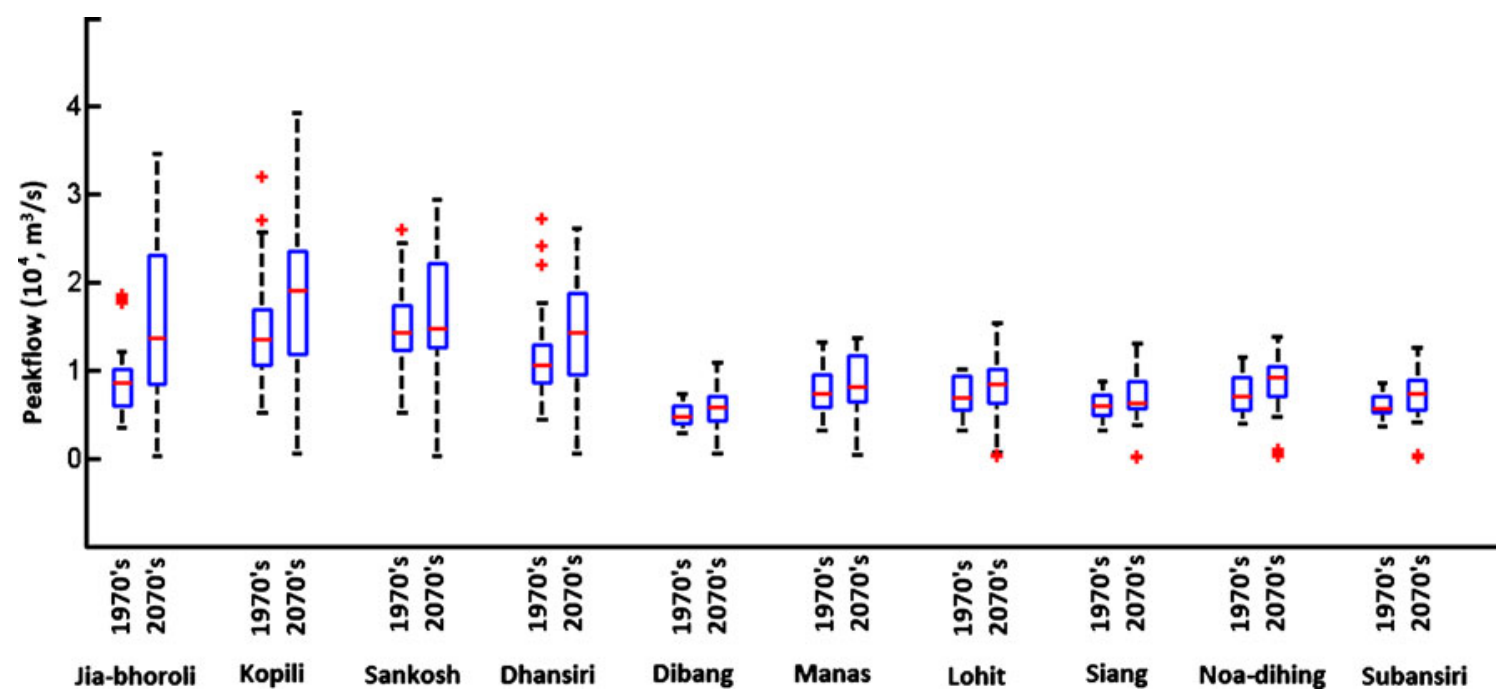

Figure 16. Changes in annual peak discharge series of the major tributaries of the Brahmaputra.

catchment areas above Tezpur, and the same waves pass through the middle and lower reaches of the river. The tributaries confluencing after Tezpur are found not to generate any new flood waves but contribute in increasing the flood volume and peak discharge.

The duration of the flood wave $\left(T_{d}\right)$ is another important character in view of its impact in terms of the inundation period and the consequences of the same on the socio-economic activities of the valley. As depicted in figure 14, the number of longer-duration flood waves during the premonsoonal season has been found to be increased. The median value of the durations of all the flood waves in the 30 years simulation period has increased from 15.7 days for the baseline period to 20.1 days for the future projected period for the three river gauging stations. For the monsoonal season this increment has been found to be from
15.2 days in the baseline years to 19.3 days for the future projected period. Also, some extreme events have also been observed for the pre-monsoonal period, which is an indication of greater variability of the future flood characteristics.

Time to peak $\left(T_{P}\right)$, i.e., time taken from the arrival of the wave to reach its peak, is another important character of the flood waves in view of its impact on the time availability for implementing an effective disaster mitigation plan. The median value of $T_{P}$ has been found to be increased from 7 days in the baseline period to 9 days for the projected period in both Tezpur and Dhubri gauging stations for the pre-monsoonal season (figure 15). However, at the gauging station of Guwahati, this increment has been found to be from 7 days to 8 days for the projected period. Interestingly, the time to peak for the monsoonal flood events has not shown any significant change, although some 


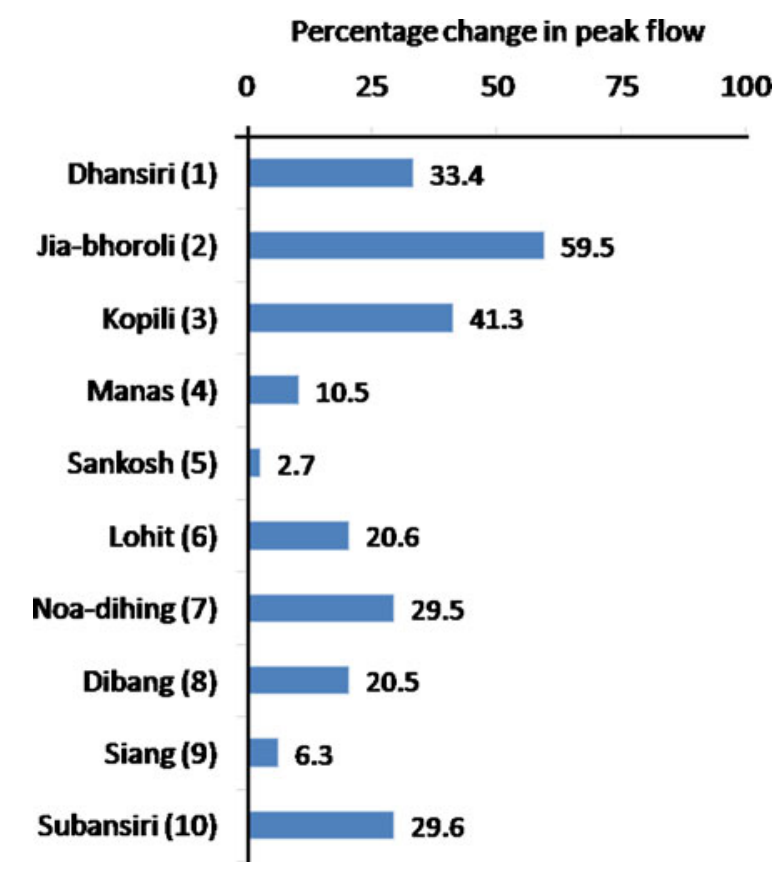

Figure 17. Percentage changes in peak discharge of the tributaries and their relative flashiness (relative flashiness ranks are provided in brackets).

extreme flood events have been observed during this period.

\subsection{Effect of climate change on the peak discharge at tributary level}

As shown in figure 16, the peak annual discharge for all the major tributaries are likely to be increased under the climate change scenario. Flashiness of a river can be qualitatively correlated with the coefficient of variation $(\mathrm{CV})$ of the annual peak discharge series of that river. Higher coefficient of variation indicates flashier nature of the river. For 10 major tributaries the CVs of annual peak discharge series have been computed and the tributaries have been ranked based on these coefficients. These ranks along with the changes in the median value of the peak flow series under climate change scenario are shown in figure 17. From this figure it can be observed that, in general, the flashier rivers have observed greater change in their annual peak discharge; however, the rivers having moderate to low flashiness coefficient have not followed any clear trend. This is because the flashiness of the river is not only the function of the basin characteristics but also depends upon the characteristics of the rainfall events and their temporal variation. Thus, only when the dominating basin characteristics override the rainfall variability, the changes in peak discharges follow a significant trend.

\subsection{Likelihood assessment of the hydrological trends}

The likelihood of the direction of the change in flood wave characteristics under climate change scenario is presented in table 5 . In the assessment all the hydrological years were given equal weightage. The direction of change has been assessed with reference to the hydrological conditions of the baseline period of 1961-1990, following Västilä et al (2010). The long-term future predicted hydrological simulation results of 2071-2100 have been compared with that of the baseline period, to assess the significance and likeliness of the simulated changes. To nullify the residual biasness, if any, in the climate model, the output of the hydrological model using the same PRECIS meteorological data has been used for the analysis. The changes have been categorized as 'very likely' if the changes in the median value, the 25 percentile value and the 75 percentile value of the long-term series data are all found to be in same direction for at least two gauging stations out of the three considered; and

Table 5. Likelihood assessment of the changes in flood characteristics due to climate change.

\begin{tabular}{llll}
\hline Season & Flood characteristics & $\begin{array}{c}\text { Direction of } \\
\text { change }\end{array}$ & Description \\
\hline Pre-monsoon & Peak flow & $\uparrow \uparrow$ & Very likely to increase \\
& Flood duration & $\uparrow \uparrow$ & Very likely to increase \\
& Time to peak & $\uparrow \uparrow$ & Very likely to increase \\
No. of flood waves & $\uparrow$ & Likely to increase \\
& Peak flow & $\uparrow \uparrow$ & Very likely to increase \\
& Flood duration & $\uparrow \uparrow$ & Very likely to increase \\
Timnual & No. of flood waves & $=$ & Likely to be same \\
Long term average & Mean annual flow & $\downarrow \downarrow$ & Very likely to decrease \\
& Variability of the events & $\uparrow \uparrow$ & Very likely to increase \\
& No. of extreme events & $\uparrow$ & Likely to increase \\
& No. of moderate events & $\uparrow$ & Likely to be increase over a threshold value \\
& & $\underline{\downarrow}$ & Likely to decrease up to a limiting value \\
\hline
\end{tabular}


categorized as 'likely' if any of the changes in the median value, 25 percentile value and of the 75 percentile value of the long-term series data are found to be in opposite direction than others for at least two gauging stations out of the three considered. In the latter case, the direction change in the median value has been considered. From this likelihood analysis, the changes predicted for the pre-monsoonal and monsoonal peak discharge, flood duration and number of monsoonal flood waves per year are categorized as 'very likely', while the changes in the number of pre-monsoonal flood waves per year and the variability of the events are categorized as 'likely'. Changes in the extreme and moderate flood events have been found to be limited by certain threshold value.

\section{Conclusions}

In the present study, a physically based macro-scale distributed hydrological model has been calibrated and validated to obtain the flood wave characteristics and discharge variation at both basin and tributary scales. The hydrological model has been found to predict the time scale of flood wave characteristics and peak discharge within the acceptable accuracy range. The possible extent of the changes in the flood wave characteristics due to the projected climate change in long-term scenario have been assessed using this calibrated hydrological model. The output of an RCM simulation has been used after bias correction for this purpose.

The analysis of the simulation result suggests that for both the pre-monsoonal and monsoonal seasons, peak discharges and flood wave durations are expected to increase under the projected climate change scenario. However, fewer of flood waves in the monsoon season with increased flood volume are expected in the basin under the projected climate change scenario, while for the pre-monsoonal season the number of waves and their peak discharges both are expected to be increased. The increment in the peak flow in the monsoon season is likely to be more for the moderate events, while the extreme events with higher return periods are expected to show lesser increment. Variability of the events is expected to increase under the projected climate change scenario. Almost all the tributaries of the Brahmaputra river system are likely to carry an increased peak discharge with greater variation in annual peak discharge series.

To obtain the statistical trend of the hydrological change, a long series of runoff simulation has been analysed by likelihood analysis. The likelihood analysis shows that most of the flood wave characteristics are very likely to change, except the time of peak, due to the effect of the projected climate change. This study was focused with one climatic change scenario, but other RCM/GCM output scenarios will be used in future to evaluate these obtained trends thoroughly. These obtained trends are, however, essential for the planning of flood hazard mitigation, morphological change assessments, future agricultural water availability and other water related issues of the valley thoroughly.

\section{Acknowledgements}

The authors hereby acknowledge the financial assistance of the Space Application Centre (SAC) of Indian Space Research Organization (ISRO) for the present work. They are also thankful to Dr Praveen Gupta of SAC, ISRO, for his generous contribution of the meteorological dataset.

\section{Appendix A}

\section{Mathematical formulation of the hydrological model (RISE)}

Rice Irrigation System Evaluation (RISE) model (Dutta and Zade 2003; Mishra et al 2008) is a distributed physically based hydrological model in which surface and subsurface hydrologic processes have been conceptualized for a paddy agriculture dominated watershed in tropical/subtropical regions. The mathematical formulation of each hydrological process used in this model (refer figure 4 for the hydrological process description) is briefly described below:

\section{A.1 Infiltration process}

\section{A.1.1 Macropore-dominated vegetated hillslope}

Infiltration process in a vegetated hillslope is controlled by micropore and macropore flow mechanism in its subsoil formations (Sarkar et al 2006). But in tropical/subtropical regions, subsurface flow mechanism is governed mainly by both the soil matrix and macropore networks as the monsoon season advances to its peak and generally have concentrated rainfall over short time span; however, during the onset of monsoon season soil matrix flow primarily governs the infiltration rate. If the maximum infiltration rate of a vegetated hillslope is $f_{\max }$, due to combined effect of micropores and macropores, the resulting overland flow rate $(R)$ can be expressed (Sarkar et al 2008) as:

$$
\begin{array}{ll}
R=0, & \text { when } i \leq f_{\max } \\
R=i-f_{\max }, & \text { when } i \geq f_{\max }
\end{array}
$$

where $i$ is the rainfall intensity. 


\section{A.1.2 Paddy-cultivation-dominated agricultural lands}

The hard pan formation below the plow layer, typical in paddy agricultural system, having very low permeability (typically, 2-4 $\mathrm{mm} / \mathrm{h}$ ) inhibits the infiltration of ponded field water. A permeability factor has been introduced for defining this special infiltration behaviour. If $h$ is the retaining depth in the paddy field, $h_{1}$ and $h_{2}$ are the depth of plow layer and the depth of hard pan formation respectively, using the two layer Green-Ampt model, the infiltration rate at the bottom of the lowest layer, i.e., the hard pan formation can be formulated as:

$$
f=\frac{k_{1} k_{2}\left(h_{1}+h_{2}+h+\Psi_{1}\right)}{h_{1} k_{2}+h_{2} k_{1}}
$$

where $\Psi_{1}$ is the suction pressure of the saturated plow layer; $k_{1}$ and $k_{2}$ are saturated hydraulic conductivities of plow layer and hard pan formations respectively. The value of $k_{2}$ can be obtained from the relation: $k_{2}=\left(k_{1} / r\right)$, where $r$ is the degree of soil impermeability (dimensionless) due to the formation of hard pan layer.

\section{A.1.3 Semi-impervious urban area}

The dominant runoff generation mechanism in this type of area is Hortonian infiltration excess runoff generation process. The infiltration rate for this case can be obtained by the analytical solution of one dimensional Richard's equation for saturated soil horizon. This results in Philip's two-term infiltration equation, given as:

$$
f_{c}(t)=0.5 S t^{-0.5}+A_{0}
$$

where $f_{c}(t)$ is the potential infiltration rate $(\mathrm{mm} / \mathrm{h}), S$ is the sorptivity and $A_{0}$ is the gravitational infiltration rate $(\mathrm{mm} / \mathrm{h})$.

\section{A.2 Water budgeting}

\section{A.2.1 Macropore-dominated vegetated hillslope}

Storage of water in the root zone is primarily contributed by the soil matrix as the pore water in the macropore zone has very short resident time. If $S_{r}$ be the subsurface storage at time $t$, the mass balance equation considering only evapotranspiration losses in the root zone can be expressed as:

$$
\begin{aligned}
& \frac{d s_{r}}{d t}=i-E T_{\text {actual }}+f_{\text {ex }} \quad \text { when } i \leq f_{\max } \\
& \frac{d s_{r}}{d t}=f_{\text {max }}-E T_{\text {actual }}+f_{\text {ex }} \quad \text { when } i>f_{\max }
\end{aligned}
$$

where $E T_{\text {actual }}$ is the actual evapotranspiration rate $(\mathrm{mm} / \mathrm{h})$ and exfiltration rate from the soil subsurface is $f_{\text {ex }}(\mathrm{mm} / \mathrm{h})$. All the rainfall above the maximum storage capacity, $S_{\max }$, contributes to subsurface recharge.

\section{A.2.2 Paddy-cultivation-dominated agricultural lands}

The retention depth $(h)$ of water in a paddy field can be formulated as:

$$
\frac{d h}{d t}=\left(i-f-E T_{\text {actual }}-h_{o v}+f_{\mathrm{ex}}\right) .
$$

If $h_{r e t}$ is the maximum retention depth of the field, the unit discharge of over-spilled water in the field $h_{o v}$ is related to the retention depth $(h)$ as:

$$
\begin{gathered}
h_{o v}=\frac{h-h_{r e t}}{\Delta t} \quad \text { when } h \leq h_{r e t} \\
\text { otherwise } h_{o v}=0
\end{gathered}
$$

where $\Delta t$ is the simulation time interval. Retention depth $(h)$ at the previous time step has been used in equation (A1:6) without any significant error in water budgeting. Thornthwaite's formula has been used to determine potential evapotranspiration from daily temperature data and subsequently multiplied by a seasonal crop coefficient, which can be taken in the range of $0.9-1$ for the region, to obtain the actual evapotranspiration ( $\left.E T_{\text {actual }}\right)$ for paddy fields.

\section{A.2.3 Semi-impervious urban areas}

Water held in the subsurface layer of this zone has not been considered for water budgeting unless any exfiltration process occurred. This is due to the fact that in this area the water held in subsurface zone is negligible.

\section{A.2.4 Wetlands as permanent sinks}

During monsoon season, wetlands receive precipitation and lateral subsurface flow. It loses some part of its storage as evaporation. At the macroscale hydrologic condition, it works as a local hydrologic sink.

\section{A.3 Subsurface flow component}

Subsurface flow approximation (Beven and Kirkby 1979) has been followed for the model to calculate the dynamics of saturated excess zone and direct subsurface flow contribution to the channel. The soil moisture local deficit at each grid cell can be 
expressed by the following equation for a spatially averaged recharge rate $f$ :

$$
S_{i}=\bar{S}+m\left[\left(\lambda-\ln \frac{a}{\tan \beta}\right)-\left(\ln T_{0}-\delta\right)\right]
$$

where $S_{i}$ is the local storage deficit per unit plane area $(\mathrm{m}), \bar{S}$ is the lumped storage deficit $(\mathrm{m}), m$ is a parameter controlling the rate of decline of transmissivity with increasing storage deficit $(\mathrm{m})$, $T_{0}$ is the local saturated transmissivity $\left(\mathrm{m}^{2} / \mathrm{s}\right)$, and the two topographic constants $\lambda$ and $\delta$ are defined as:

$$
\lambda=\frac{1}{A} \sum_{j} A_{j} \ln \left(\frac{a}{\tan \beta}\right)
$$

and

$$
\delta=\frac{1}{A} \sum_{j} A_{j} \ln T_{0}
$$

where $A$ is the total area of the catchment $\left(\mathrm{m}^{2}\right)$, and $A_{j}$ is the area associated with the point $j\left(\mathrm{~m}^{2}\right)$, $\tan \beta$ represents the local hydraulic gradient and $\alpha$ is the area of the hillslope per unit contour length (m). The detailed derivations of this can be found in Arora and Boer (2001).

Integration of the equation (A1:7) over the entire watershed gives the mean soil moisture deficit $\left(\bar{S}_{t}\right)$ at time $t$ and can be expressed as:

$$
\bar{S}_{t}=\bar{S}_{t-1}+\left(q_{t-1}-f\right) \Delta t
$$

where $q_{t-1}$ is the runoff per unit catchment area $(\mathrm{m} / \mathrm{s})$ at time $(t-1)$, and $f$ is the average recharge from paddy fields and vegetated hillslope $(\mathrm{m} / \mathrm{s})$, while $\Delta t$ is the time interval used for the model simulation. For a particular grid, exfiltration $\left(f_{e x}\right)$ has been considered to be equal to the magnitude of $S_{i}$ when the local deficit is negative.

The subsurface flow rate $q_{b}$ per unit length $\left(\mathrm{m}^{2} / \mathrm{s}\right)$ to the channel is given as:

$$
q_{b}=\exp (-(\lambda-\delta)) \exp \left(-S_{i} / m\right)
$$

The mean exfiltration rate $\left(q_{0}\right)$ from saturated area can be obtained from

$$
q_{0}=\left(\frac{1}{A t}\right) \int_{A s}\left\{-S_{i}-\Delta t\right\} d A
$$

where $A_{s}$ is the saturated area of the catchment $\left(\mathrm{m}^{2}\right)$.

\section{A.4 Channel routing}

\section{A.4.1 Lateral flow to the channel segments}

The contributing area of each of the delineated channel segment is obtained based on 'the steepest gradient' method from a digital elevation dataset.
The total runoff generated in the contributing area of each channel segment from the above-mentioned three classes reaches in the form of lateral flow to that segment. The lateral flow rate is given by:

$$
\begin{aligned}
q_{l}= & q_{b}+\frac{1}{A}\left[\int_{A_{p}} h_{o v} d A+\int_{A_{s m}}\left(\frac{S_{i}}{\Delta t}+i\right) d A\right. \\
& +\int_{A_{u m}} R d A+\int_{A_{s h}}\left(\frac{S_{i}}{\Delta t}+i\right) d A \\
& \left.+\int_{A_{u h}}(i-f) d A\right]
\end{aligned}
$$

where $A_{p}, A_{s m}, A_{u m}, A_{s h}$, and $A_{o h}$ are the areas of paddy fields $\left(\mathrm{m}^{2}\right)$, area in vegetated hillslopes giving saturation excess overland flow $\left(\mathrm{m}^{2}\right)$, infiltration excess overland flow area in vegetated hillslopes $\left(\mathrm{m}^{2}\right)$, saturation excess overland flow area in semi-impervious urban clusters $\left(\mathrm{m}^{2}\right)$ and infiltration excess overland flow area in semi-impervious clusters $\left(\mathrm{m}^{2}\right)$, respectively.

\section{A.4.2 Linearized channel routing}

Using kinematic wave approximation the continuity and momentum equations for a steep channel can be expressed as a second-order partial differential equation (Rajyalakshmi and Dutta 2006) with the boundary conditions $Q(0, t)=s(t), Q(x, 0)=0$ and $Q(\infty, t)=0$ as:

$$
\frac{\partial Q}{\partial t}=D \frac{\partial^{2} Q}{\partial X^{2}}+C \frac{\partial Q}{\partial X}
$$

where $Q$ is the discharge $\left(\mathrm{m}^{3} / \mathrm{s}\right), D$ is the diffusion coefficient $\left(\mathrm{m}^{2} / \mathrm{s}\right), C$ is the kinematic celerity $(\mathrm{m} / \mathrm{s}), t$ is the time $(\mathrm{s})$ and $X$ is the distance from upstream end $(\mathrm{m})$. If a uniformly distributed lateral impulse enters the channel over a reach length $S=[(X=S)-(X=0)]$, the solution of the equation (A1:13) becomes

$$
\begin{aligned}
Q_{i}^{\prime}(S, t) & \int_{0}^{S} \frac{X}{2\left(\pi D t^{3}\right)^{1 / 2}} \exp \left[-\frac{(X-C t)^{2}}{4 D t}\right] d X \\
= & \frac{D^{1 / 2}}{(\pi t)^{1 / 2}}\left\{\exp \left[\frac{(C t)^{2}}{4 D t}\right]-\exp \left[-\frac{(X-C t)^{2}}{4 D t}\right]\right\} \\
& +\frac{C}{2}\left\{\operatorname{erf}\left[\frac{C t}{2(D t)^{1 / 2}}\right]+\operatorname{erf}\left[\frac{(S-C t)}{2(D t)^{1 / 2}}\right]\right\}
\end{aligned}
$$

where erf represents an error function. The solution of equation (A1:14) at distance $S$, when a uniformly 
distributed lateral impulse of $q_{1}$ enters the channel over a reach length $\Delta X=\left[\left(X=X^{*}\right)-(X=0)\right]$ with $X^{*}<S$, is obtained directly from

$$
Q_{f(\Delta X)}^{\prime}(S, t)=\frac{q_{l}}{\Delta X}\left[Q^{\prime}(S, t)-Q^{\prime}(S-\Delta X, t)\right] .
$$

\section{References}

Abbott M B, Bathurst J C, Cunge J A, O'Connell P E and Rassmussen J 1986 An introduction to the European Hydrological System - Systeme Hydrologique Europeen, 'SHE', 2: Structure of a physically-based, distributed modelling system; J. Hydrol. 87 61-77.

Akhtar M, Ahmad N and Booij M J 2008 The impact of climate change on the water resources of HindukushKarakorum-Himalaya region under different glacier coverage scenarios; J. Hydrol. 355 148-163.

Akhtar M, Ahmad N and Booij M J 2009 Use of regional climate model simulations as input for hydrological models for the Hindukush-Karakorum-Himalaya region; Hydrol. Earth Syst. Sci. 13 1075-1089.

Arora V K and Boer G J 2001 Effects of simulated climate change on the hydrology of the major river basins; J. Geophys. Res. 106 3335-3348.

Bathurst J C 1986 Physically based distributed modelling of an upland catchment using the Systeme Hydrologique Europeen; J. Hydrol. 105 79-102.

Beven K and Kirkby M J 1979 A physically based, variable contributing area model of basin hydrology; Hydrol. Sci. Bull. 24(1) 43-69.

Buytaert W, Vuille M, Dewulf A, Urrutia R, Karmalkar A and Celleri R 2010 Uncertainties in climate change projections and regional downscaling in the tropical Andes: Implication for water resources management; Hydrol. Earth Syst. Sci. 14 1247-1258.

Cameron D, Beven K and Naden P 2000 Flood frequency estimation by continuous simulation under climate change (with uncertainty); Hydrol. Earth. Syst. Sci. 4(3) 393-405.

Chang H and Jung I W 2010 Spatial and temporal changes in runoff caused by climate change in a complex large river basin in Oregon; J. Hydrol. 388 186-207.

Datta B and Singh V P 2004 Hydrology; In: The Brahmaputra Basin Water Resources (eds) Singh V P, Sharma N, Shekhar C and Ojha P (Netherlands: Kluwer Academic Publishers), pp. 139-195.

Dutta S and Zade M 2003 RISE - A distributed hydrologic model for Rice agriculture: Concept and evaluation. In: Watershed Hydrology (eds) Singh V P and Yadava R N (India: Allied Publishers), pp. 240-251.

Gain A K, Immerzeel W W, Sperna Weiland F C and Bierkens M F P 2011 Impact of climate change on the stream flow of the lower Brahmaputra: Trends in high and low flows based on discharge-weighted ensemble modelling; Hydrol. Earth Syst. Sci. 15 1537-1545.

Ghosh S and Dutta S 2010 Impact of climate and land use changes on the flood characteristics of the Brahmaputra basin; In: Proceedings of National Conference on Hydraulics, Water Resources, Coastal and Environmental Engineering (HYDRO-2010), 16-18 December 2010, MMU, Mullana, India.

Graham L P, Andreasson J and Carlsson B 2007 Assessing climate change impacts on hydrology from an ensemble of regional climate models, model scales and linking methods - a case study on the Lule River basin; Clim. Change 81 293-307.
Hadley Centre 1997 Climate change and its impacts: A global perspective; Department of the Environment, Transport and the Regions/Met. Office, Bracknell.

He H, McGinnis J W, Song Z and Yanai M 1987 Onset of the Asian Summer Monsoon in 1979 and the effect of the Tibetan Plateau; Mon. Weather Rev. 115 1966-1995.

Hydro1k Dataset, USGS, http://eros.usgs.gov/\#/Find Data/Products_and_Data_Available/gtopo30/hydro, visited on October 17, 2011.

Ionia Glob Cover Portal, European Space Agency, http://ionia1.esrin.esa.int/, visited on October 17, 2011.

IPCC 2001 Climate change 2001: The scientific basis (eds) Houghton J T, Ding Y, Griggs G, Noguet M, Van der Linden P, Dai X, Maskell K and Johnson C A, Cambridge University Press, Cambridge.

Julien P Y and Saghafian B 1991 CASC2D user manual a two dimensional watershed rainfall-runoff model; Colorado State University, Fort Collins, USA, Civil Engineering Report CER90-91PYJ-BS -12.

Julien P Y, Saghafian B and Ogden F L 1995 Raster-based hydrological modelling of spatially-varied surface runoff; Water Resour. Bull. 31(3) 523-536.

Karmaker T and Dutta S 2010 Generation of synthetic seasonal hydrographs for a large river basin; J. Hydrol. 381 $287-296$.

Kay A L, Jones D A, Crooks S M, Calver A and Reynard N S 2006 A comparison of three approaches to spatial generalization of rainfall runoff models; Hydrol. Process. $203953-3973$.

Kumar R and Chatterjee C 2005 Regional flood frequency analysis using L-moments for North Brahmaputra Region of India; J. Hydrol. Eng. 10(1) 1-7.

Kundzewicz Z W, Mata L J, Arnell N W, Doll P, Kabat P, Jimenez B, Miller K A, Oki T, Sen Z and Shiklomanov IA 2007 Freshwater resources and their management; In: Climate Change 200\%: Impacts, Adaptation and Vulnerability, Contribution of Working Group II to the Fourth Assessment Report of the Intergovernmental Panel on Climate Change (eds) Parry M L, Canziani $\mathrm{O}$ F, Palutikof J P, Van der Linden $\mathrm{P}$ J and Hanson C E (Cambridge, UK: Cambridge University Press), pp. 173-210.

Mirza M M Q 2002 Global warming and changes in the probability of occurrence of floods in Bangladesh and implications; Global Environ. Change 12 127-138.

Mirza M M Q, Warric R A and Ericksen N J 2003 The implications of climate change on floods of the Ganges, Brahmaputra and Meghna rivers in Bangladesh; Clim. Change 57 287-318.

Mishra S K, Sarkar R, Dutta S and Panigrahy S 2008 A physically process based hydrological model for Paddy agriculture dominated hilly watersheds in Tropical region; J. Hydrol. 357 389-404.

Ogden F L and Julien P Y 1994 Runoff model sensitivity to radar rainfall resolution; J. Hydrol. 158 1-18.

Rajyalakshmi N V and Dutta S 2006 Regionalization of rainfall runoff processes in rice agriculture dominated watersheds; Water Sci. Technol. 53(10) 131-139.

Reynard N S, Prudhomme C and Crooks M 2001 The flood characteristics of large UK rivers: Potential effects of changing climate and land use; Clim. Change 48 343-359.

Rogers C C M, Beven K J, Morris E M and Anderson M G 1985 Sensitivity analysis, calibration and predictive uncertainty of the Institute of Hydrology Distributed Model; J. Hydrol. 81 179-191.

Rupa Kumar K, Sahai A K, Kumar K K, Patwardhan S K, Mishra P K, Revadekar J V, Kamala K and Pant G B 2006 High-resolution climate change scenarios for India for the 21st century; Curr. Sci. 90(3) 334-345. 
Sarkar R, Dutta S and Panigrahy S 2008 Characterizing overland flow on a preferential infiltration dominated hillslope: A case study; J. Hydrol. Eng. 13(7) 563-569.

Sarma J N 2004 An overview of the Brahmaputra river system; In: The Brahmaputra Basin Water Resources (eds) Singh V P, Sharma N, Shekhar C and Ojha P (Netherlands: Kluwer Academic Publishers), pp. 72-88.

Sarma J N 2005 Fluvial process and morphology of the Brahmaputra River in Assam, India; Geomorphology $\mathbf{7 0}$ 226-256.

Soja R and Starkel L 2007 Extreme rainfalls in Eastern Himalaya and southern slope of Meghalaya Plateau and their geomorphologic impacts; Geomorphology 84 170-180.

Vadivelu S, Sen T K, Bhaskar B P, Baruah U, Sarkar D, Maji A K and Gajbhiye K S 2004 Soil series of Assam, Technical Bulletin, NBSS Publ. 101, National Bureau of Soil Survey and Land Use Planning, Indian Council of Agricultural Research, India.
Västilä K, Kummu M, Sangmanee C and Chinvanno S 2010 Modelling climate change impacts on the flood pulse in the Lower Mekong floodplains; J. Water Clim. Change $01.167-86$.

Vieux B E 2001 Distributed Hydrologic Modeling Using GIS; Water Science Technology Series; Kluwer Academic Publishers, Norwell, Massachusetts.

Vieux B E and Gauer N 1994 Finite element modelling of storm water runoff using GRASS GIS; Microcomput. Civil Eng. 9(4) 263-270.

Vieux E B, Cui Z and Gaur A 2004 Evaluation of a physics based distributed hydrologic model for flood forecasting; J. Hydrol. 298 155-177.

Wang S, McGrath R, Semmler T, Sweeney C and Nolan P 2006 The impact of the climate change on discharge of Suri River catchment (Ireland) under different climate scenario; Nat. Hazard Earth Sys. 6 387-395.

Wigmosta M S, Vail L W and Lettenmaier D P 1994 A distributed hydrology-vegetation model for complex terrain; Water Resource Res. 30(6) 1665-1679. 